Journal of Educational

and Psychological Sciences

Volume (5), Issue (34): 30 Sep 2021

$P: 50$ - 68

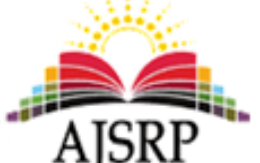

AJSRP

ISSN: 2522- 3399
مجلة العلوم

التربوية والنفسية

المجلد (5)، العدد (34): 30 سبتمبر 2021 م

ص: 50 - 68

\title{
The Effectiveness of A Proposed Unit Based on Future Problem- Solving Skills in Developing Decision- Making Skills among Government Secondary School Students in Riyadh
}

\author{
Amal Abdullah Abdulrhman Alkhudair \\ Alaa Abdulaziz Abdulrhman Abanmi \\ Al- Imam Muhammad Ibn Saud Islamic University || KSA
}

\begin{abstract}
The aim of the research is to determine the effectiveness of a proposed unit based on future problem- solving skills in developing the decision- making skills of government secondary school students in Riyadh. Using the descriptive and experimental approach, the tool was to test decision- making skills. Teacher manual; For the Occupational Problems Unit in the Work Environment. They were applied to a multi- stage randomized manner of 63 female students of the third year of secondary school, which was divided into: a control group that the occupational problems unit is taught in the work environment in the traditional way, and an experimental group that is taught using the occupational problems unit in the work environment based on problem- solving skills Future. The research found the effectiveness of the occupational problems unit in the work environment based on future problem- solving skills in developing decision- making skills as a whole. Where the experimental got a total mean (28.77 of 32) in contrast to the control obtaining a total mean (13.05 of 32 ) and the difference in favor of the experimental group, and the presence of statistically significant differences at a significance level (0.05) between the mean scores of the two groups, the experimental and the control in The post- test in decision- making skills as a whole in the vocational education course and the ETA square factor to measure the size of the effect was (0.97), and confirms that the size of the effect is (large), and the adjusted gain rate for Blake is (1.32), and reflects the great effectiveness of the proposed unit: the researcher recommends directing the curriculum officials in the Ministry of Education to take care of the development of future problem solving skills through the curriculum for their effectiveness in helping students to make decisions and benefiting from the flexibility of the vocational education curriculum in achieving future goals that help students identify their paths Professional.
\end{abstract}

Keywords: Solving future problems, vocational education, decision- making, high school students, Riyadh.

$$
\begin{aligned}
& \text { فاعلية وحدة مُقترحة قائمة على مهارات حل المشكاتلات المستقبليَّة في تَنْمية مهارات } \\
& \text { اتخاذ القرارات لدى طالِبات المرحلة الثَّانوية الحكومية بمدينة الرياض } \\
& \text { أمل بنت عبد الله بن عبد الرحمن الخضير }
\end{aligned}
$$

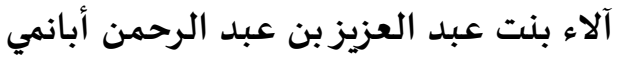

$$
\begin{aligned}
& \text { جامعة الإمام محمد بن سعود الإسلامية || المملكة العربية السعودية }
\end{aligned}
$$

المستخلص: هدف البحث إلى تحديد مدى فاعلية وحدة مقترحة قائمة على مهارات حل المشكلات المستقبلية في تنمية مهارات اتخاذ

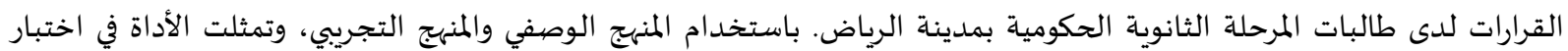


مهارات اتخاذ القرارات؛ ودليل للمعلمة؛ خاص بوحدة المشكلات المهنية في بيئة العمل. تم تطبيقهما على عينة عنقودية عشوائية

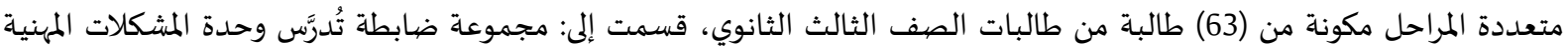

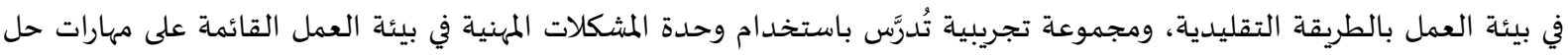

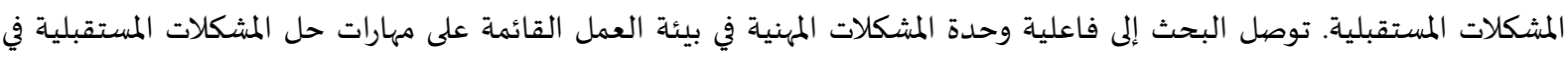

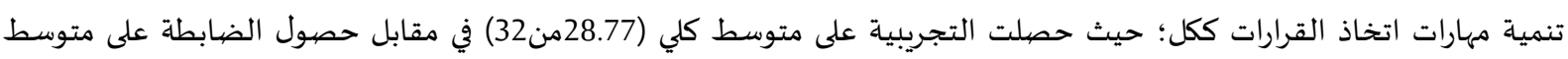

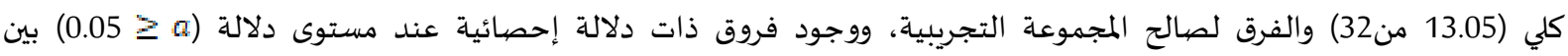

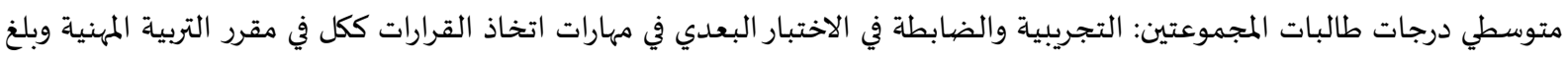

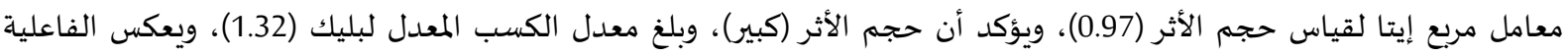

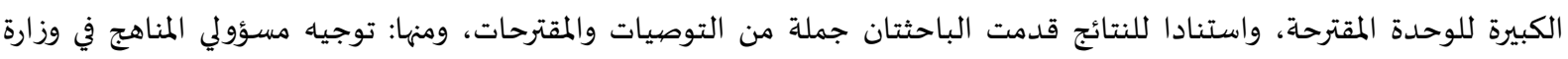

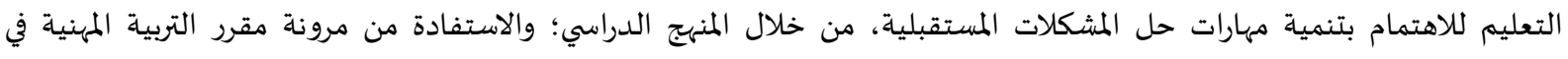
تحقيق أهداف مستقبلية تساعد الطلبة على تحديد مساراتهم المهنية. الكلمات المفتاحية: حل المشكلات المستقبلية، التربية المهنية، اتخاذ القرارات، طالبات المرحلة الثانوية، مدينة الرياض.

المقدمة.

يشهد العالم اليوم تطورات كبيرة وملموسة في عصر الصناعة والمعلومات، فقد امتدت هذه التطورات لتشمل مجال التعليم، فأصبح التعليم يهتم بإعداد الطالب للحياة، وربط خبراته التي يتعلمها داخل المؤسسات

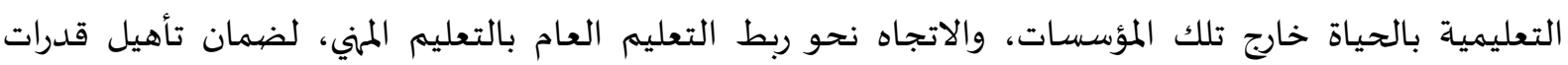
الشباب العقلية والجسمية، وإعدادهم للتعامل مع التغيرات المستمرة لعالم العمل والحياة.

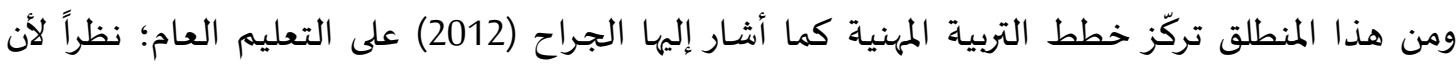

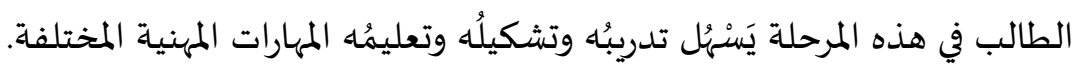

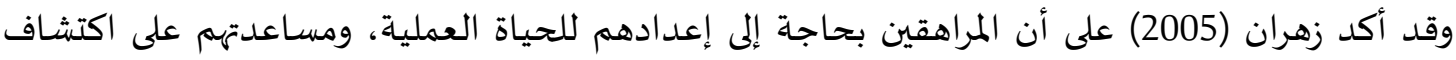

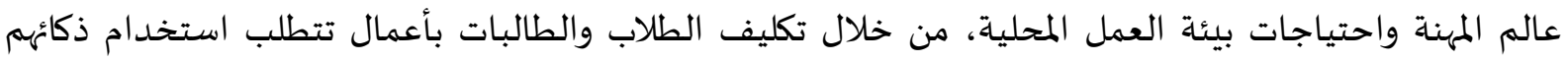

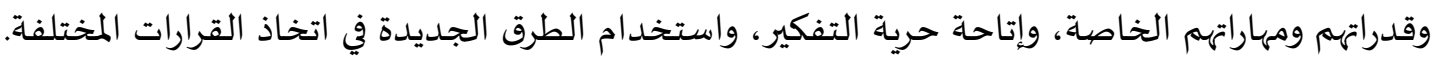

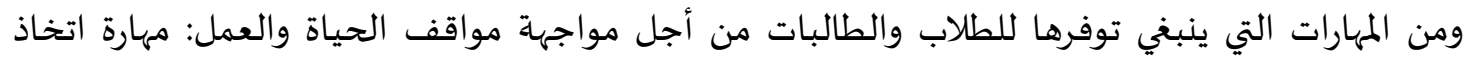
القرار، حيث توصلت دراسة الغرايبة (2016) إلى ضرورة توفير ممارسات منهجية ولا منهجية تدعم وتنميّ قدرة إنهات الطلبة على اتخاذ القرار، بحيث تنعكس مهارة اتخاذ القرار على تعلم الطلاب بشكل إيجابي.

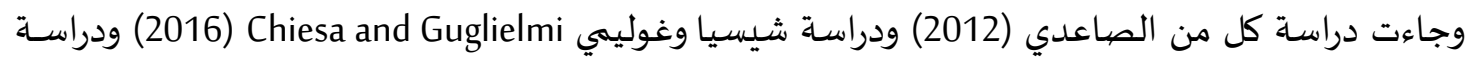

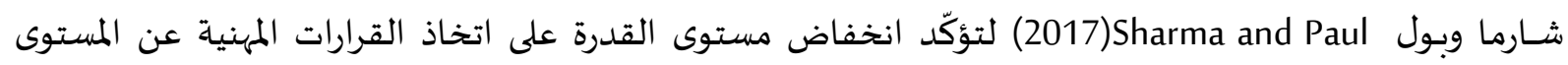
المقبول لدى طلبة المرحلة الثانوية. ويقترح المطيري (2017) ضرورة إدخال موضوع اتخاذ القرار ضمن المناهج الدراسية؛ من أجل مساعدتهه

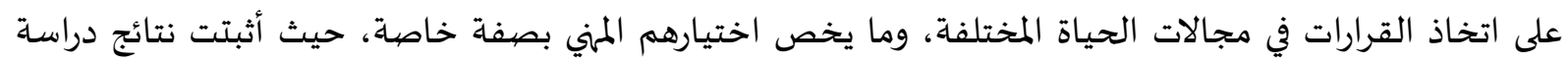

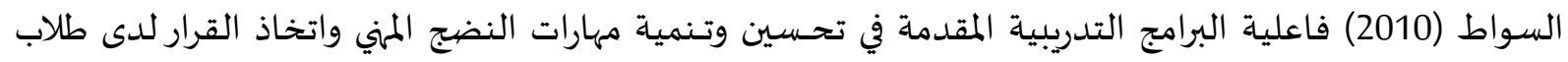
المرحلة الثانوياة.

كما تؤكد توصيات مؤتمر الجمعية السعودية للعلوم التربوية والنفسية 2018، على ضرورة تنمية مهارات التفكير الصحيحة لدى طلاب وطالبات المدارس الثانوية والجامعات، والتي تساعدهم على اكتساب مهارات اتخاذ 
القرار المني الصحيح، والتركيز على الهدف لا على الوسائل، وتعزيز البنية الأساسية بما يكفي مواكبة مخرجات وحاجات سوق العمل.

كما يرى الأغا (2016) أهمية تصميم برامج لتنمية مهارات حل المشكلات المرتبطة بمستقبل المراهقين بالمدارس ودعمها، وتوصي دراسة أبو صفية (2010) بالاهتمام ببناء مناهج تسعى إلى تنمية التوجهات المستقبلية

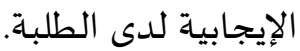

ومن أكثر الخبرات التربوية التي تساعد الطلبة على التفكير في المستقبل بصورة إيجابية ممكنة الحدوث، هي برامج حل المشكلات المستقبلية، حيث أوصت نتائج دراسة كل من الحمدي (2017) والغرايبة (2016) وأيوب (2015) وعبد الحميد (2015) ضرورة توجيا أنظار مخططي المناهج ومطوريه إلى وضع سياسات عامة لتطوير برامج دراسية تستغل قدرات ومهارات الطلاب والطالبات في التعامل مع الكم الهائل من المشكلات المستقبلية بتقديم حلول

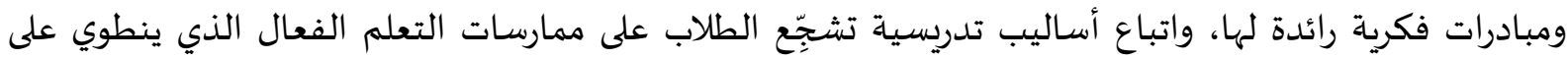
امتلاك الطلبة القدرة على اتخاذ القرار.

ويأتي هذا البحث تماشياً مع ما تتطلبه خطة المملكة العربية السعودية للتنمية المستدامة نحور تحور تفعيل

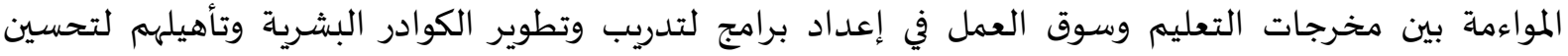
مستوى المعيشة ونوعية الحياة للمواطنين، وتنمية القوى البشرية وزيادة توظيفها، والتطوير الهيكلي للاقتصاد السعودي، والتنمية المتوازنة بين المناطق السعودية.

مشكلة البحث: نظراً للتطور السريع في مختلف مجالات الحياة العلمية والعملية والاجتماعية والتغير الذي يشهده سوق

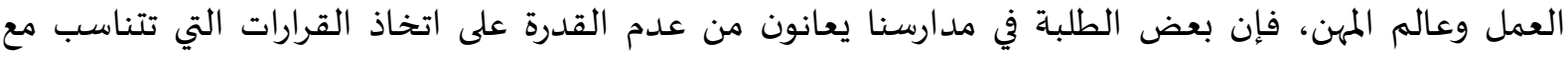

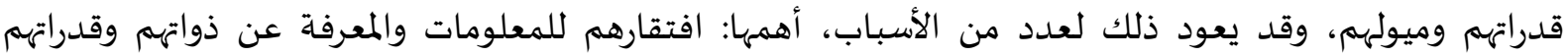

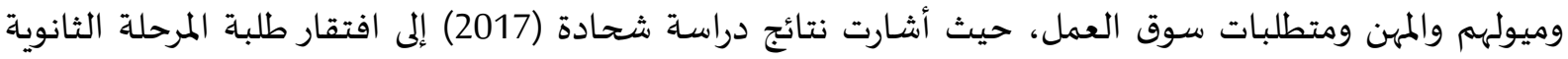

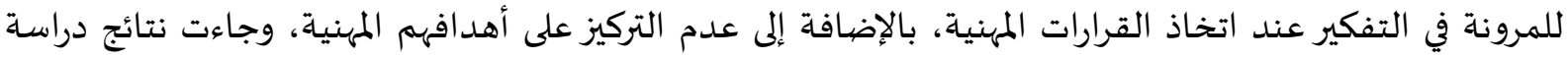

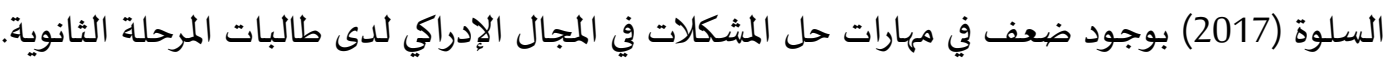

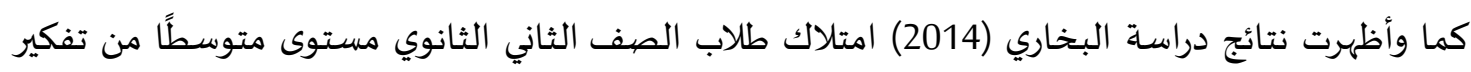

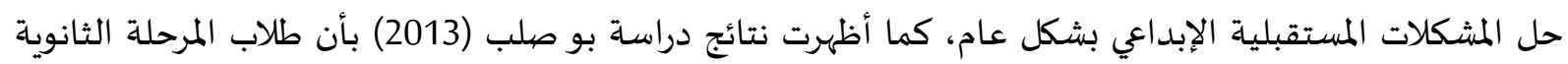

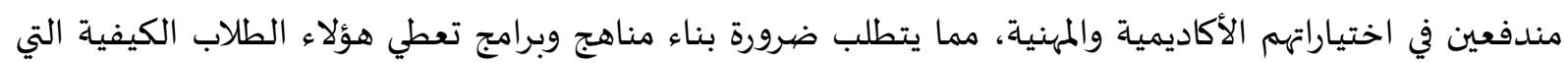

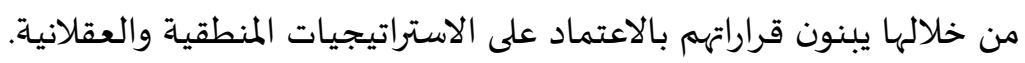

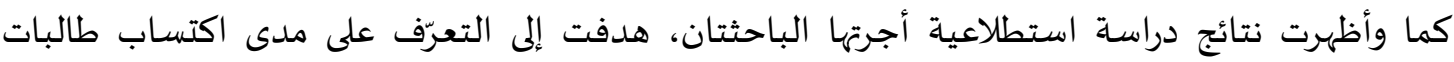

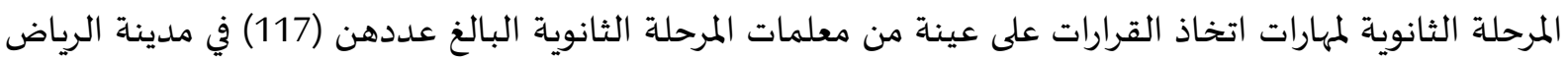

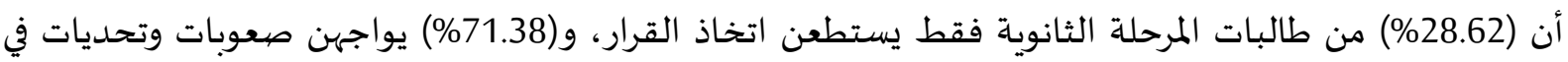

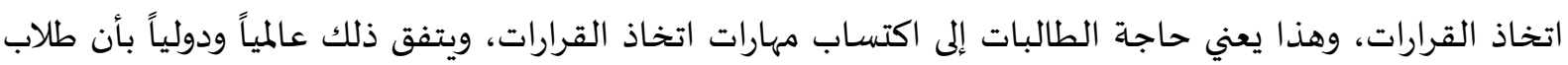

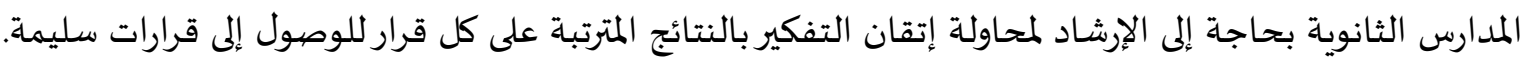

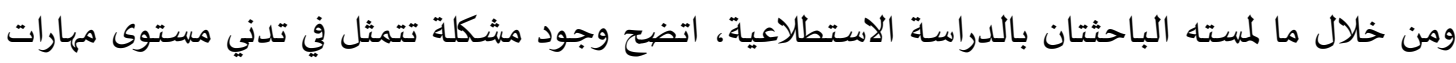

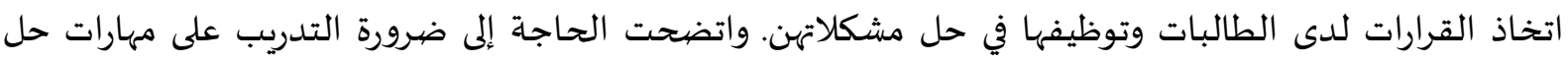


المشكلات المستقبلية في العملية التعليمية؛ من أجل تنمية مهارات اتخاذ القرارات في مقرر التربية المهنية في مدينة

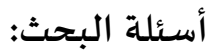
1- ما فاعلية وحدة مقترحة قائمة على مهارات حل المشكلات المستقبلية في تنمية مهارات اتخاذ القرارات ككل لدى

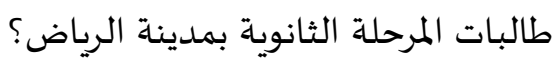
فروض البحث: للإجابة عن أسئلة البحث تم صياغة الفرض الرئيس التالي:

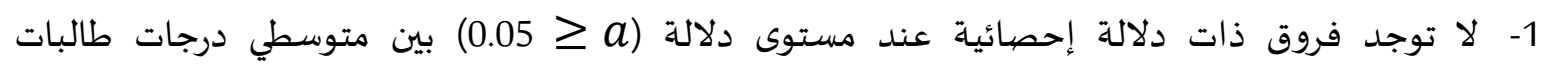

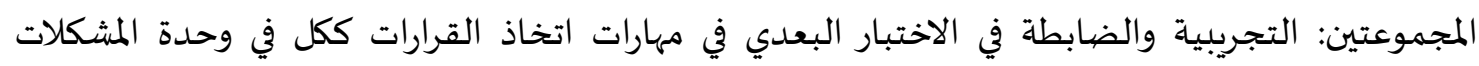

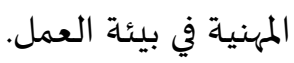
أهداف البحث: 1- بناء وحدة مقترحة قائمة على مهارات حل المشكلات المستقبلية لتنمية مهارات اتخاذ القرارات لدى طالبات المرحلة الثانوية بمدينة الرياض. 2- تحديد مدى فاعلية الوحدة المقترحة القائمة على مهارات حل المشكلات المستقبلية في مقرر التربية المهنية في

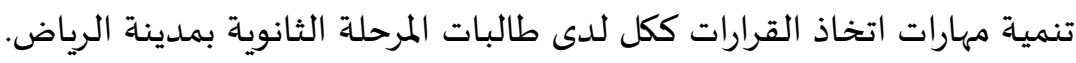

أهمية البحث: الأهمية النظرياة: - استجابةً للتوجُهات العالمية الحديثة في الاهتمام بالمستقبل، وتدريب الطالبات على مهارات حل المشكلات المستقبلية. قد تفيد في إبراز مهارات حل المشكلات المستقبلية، ومهارات اتخاذ القرارات، وما لها من دور واضح في تعزيز بناء الاقتصاد المعرفي ومجتمع المعرفة.

الأهمية التطبيقية:

- قد يفيد هذا البحث مخططي ومطوري المناهج في التعرف على أهمية تدريس مهارات حل المشكلات المستقبلية.

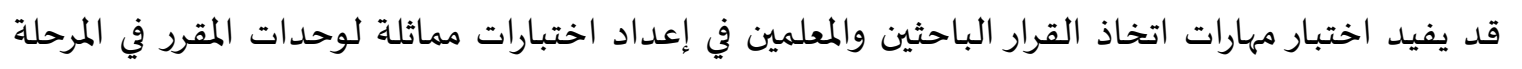
الثانوية. - يمكن من خلال البحث الحالي إعداد برامج إرشادية وتنفيذها، استناداً إلى أسس علمية نظرية لتحسين مستوى مهارات اتخاذ القرارات. حدود البحث: هالحدود الموضوعية: فاعلية وحدة قائمة على مهارات حل المشكلات المستقبلية في تنمية مهارات اتخاذ القرارات.

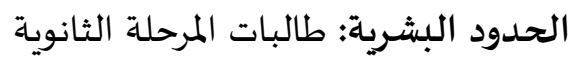
الحدود المكانية: المدارس الحكومية بمدينة الرياض في المملكة العربية السعودية. 
الحدود الزمانية: تم تطبيق البحث في الفصل الدراسي الأول من العام الدراسي 1440/1439هـ.

مصبطلحات البحث:

- الفاعليَّة: يُعرِّفها الكيلاني (2005، ص21) بأنها: "بلوغ أعلى درجات الإنجاز، وتحقيق أفضل النتائج بأقل التكاليف". م وتُعرِّفهُها الباحثتان إجرائياً بأنها: قدرة طالبات الصف الثالث الثانوي على اتخاذ القرارات بعد تدريسهن الوحدة

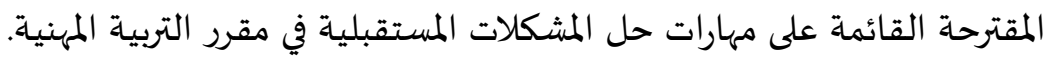

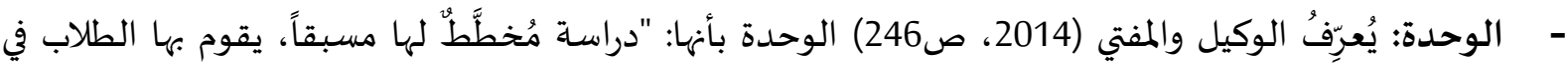

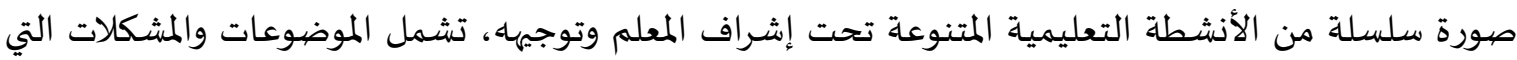

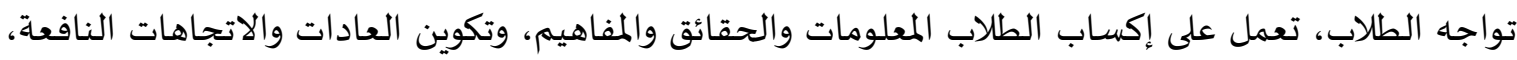
وتنمية القدرات، وإكساب بعض المهارات على إكساب اللازمة".

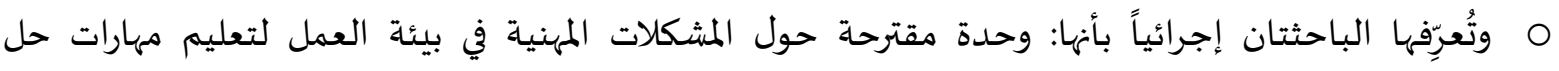

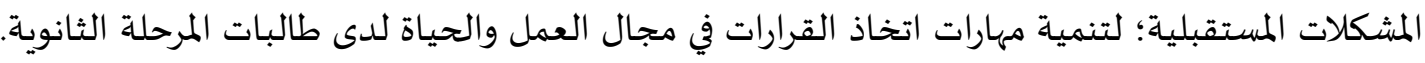

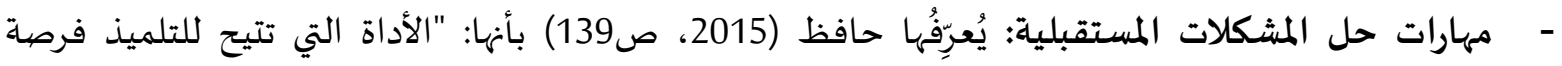
تكوين نهج شخصي خاص به؛؛ لمساعدته على التكيف مع المعطيات الجديدة، والتأقلم مع المشكلات المستقبلية التي تعترض حياته".

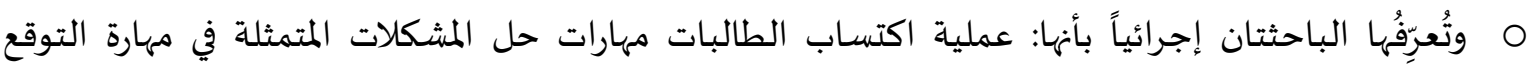

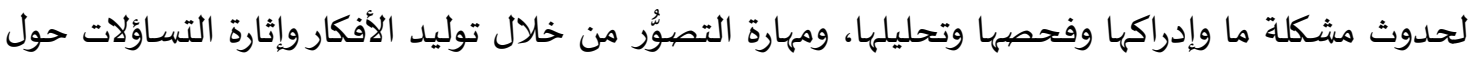

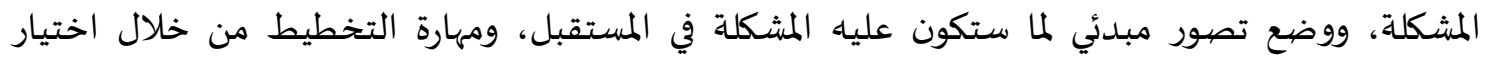

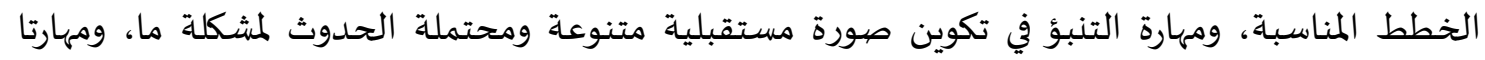

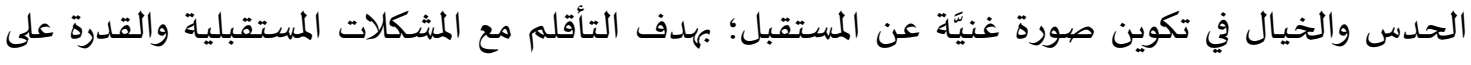

- التربية المهنية: يُعرِّها عبد الرزاق (2014، ص10) بأها: "العملية التي تجمع حول المهنة جميع القيم العلمية

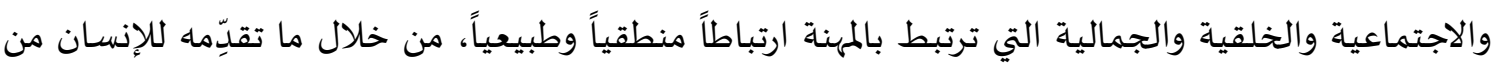
معارف يحتاج إليها لفهم عمله".

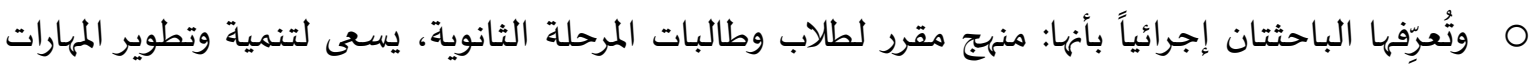

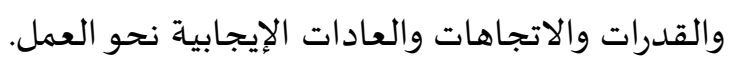

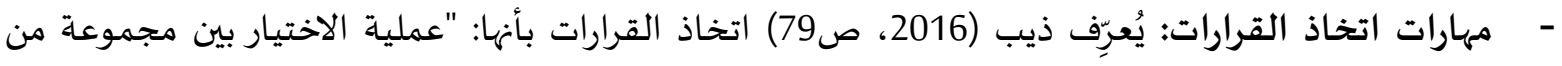

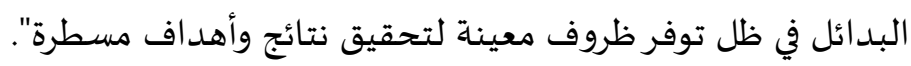

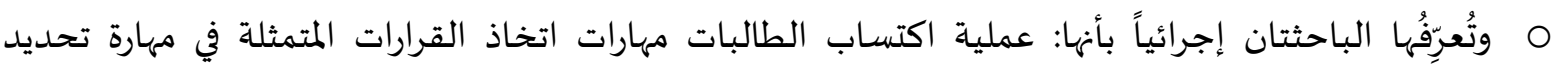

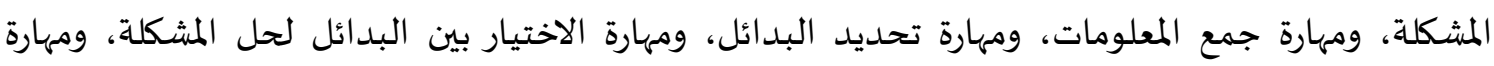

$$
\text { إصدار القرار، والتي حددتها الباحثتان من الأدب التربوي. }
$$

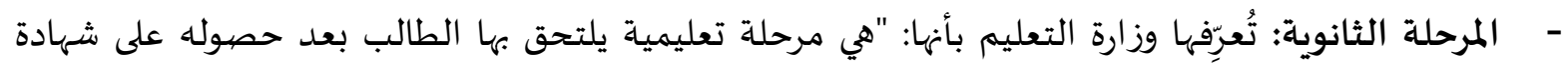

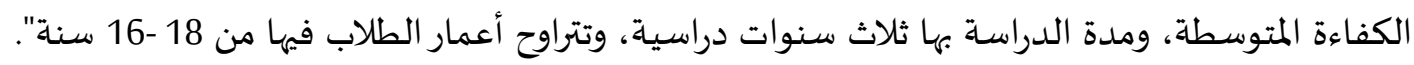




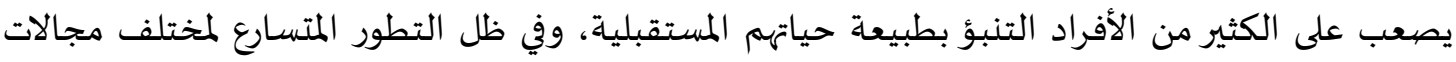

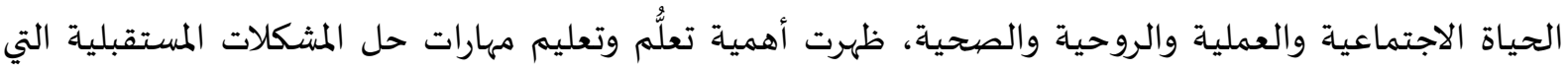

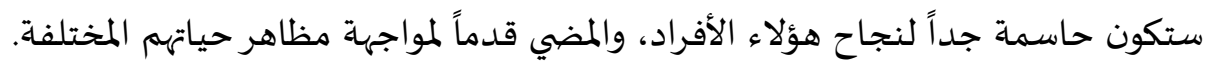

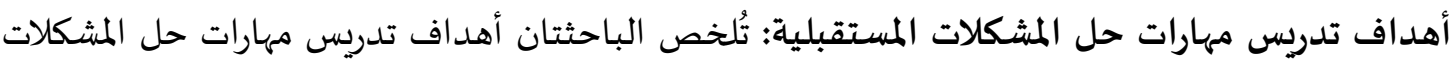

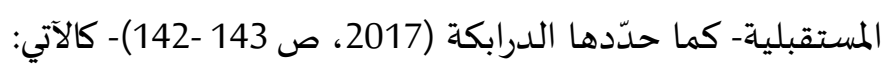

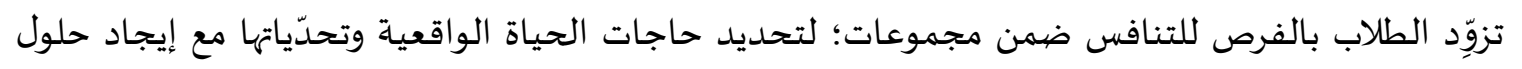
باستخدام حل المشكلات. - - مساعد الطالب على فهم المستقبل ليتعامل معه بشكل أكثر فاعلية، وباتجاهات إيجابية تساعد على إحداث تغيرات.

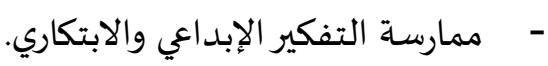

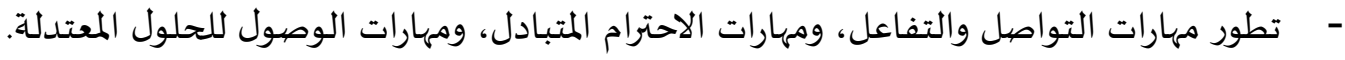

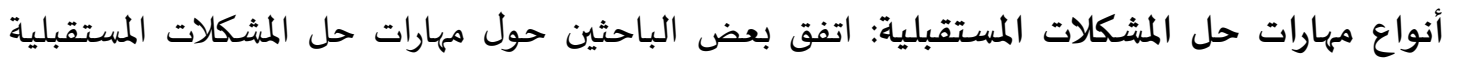

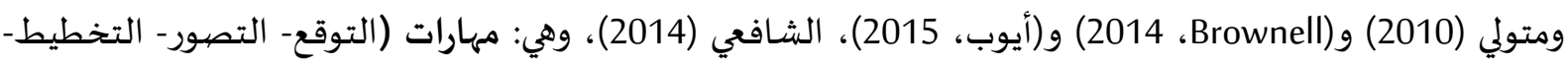

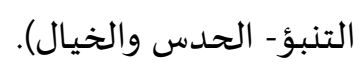

المحور الثاني: التربية المهنية المبانية

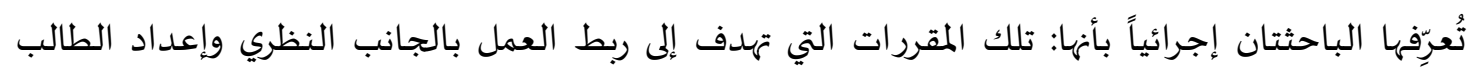

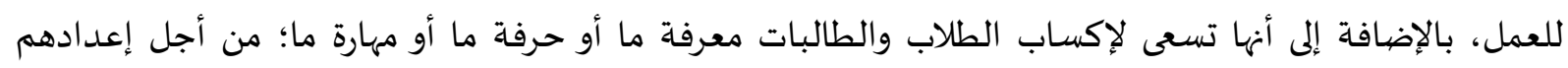

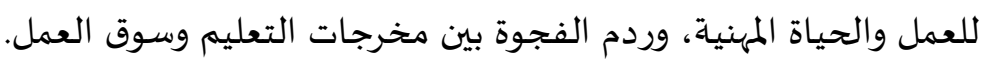

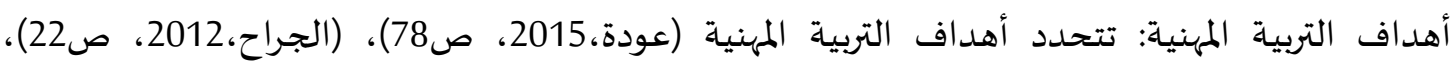
(الأحمد وقسيس، 2017، ص16 -15 المينة فيما يلي:

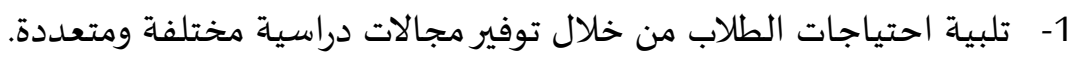

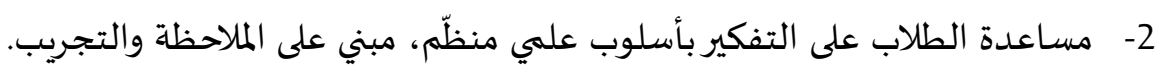

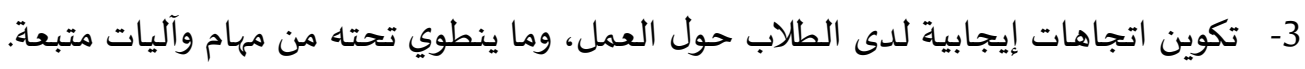

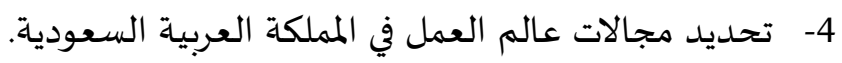

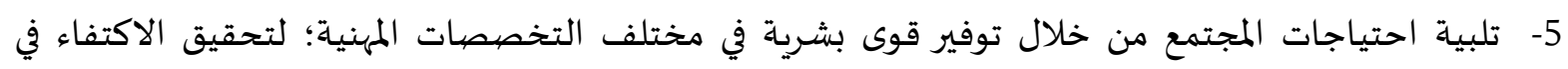

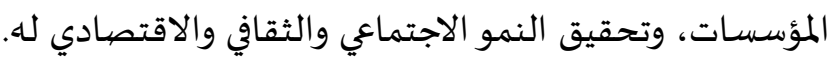

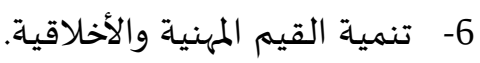

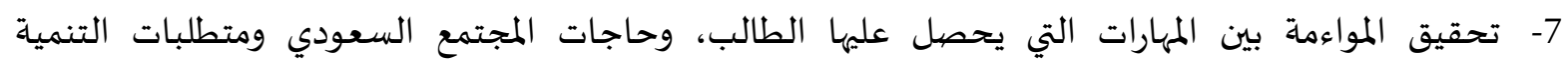

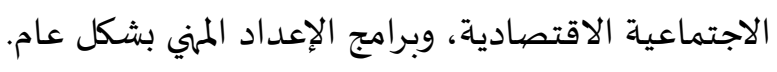


المحور الثالث: مهارات اتخاذ القرارات

تعتبر مهارات اتخاذ القرارات إحدى المهارات الضرورية للمتعلمين، فعملية اتخاذ القرار هي جزء لا يتجزأ من

حياة المتعلم. - ميلم

مهارات اتخاذ القرارات:

اتفق كلٌّ من (الوسيهي، 2010) و(علي، 2011) و(محمد، 2012) و(الحنان، 2013) و(علي، 2013)

و(المالكي، 2016) و(الزعبي، 2017) على أن المهارات الرئيسة لاتخاذ القرارات هي كما يأتي: تحديد المشكلة، وجمع

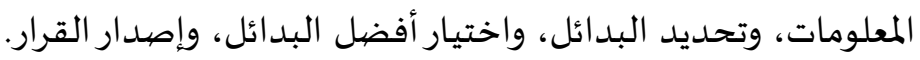

المحور الرابع: خصائص نمو طالبات المرحلة الثانوية

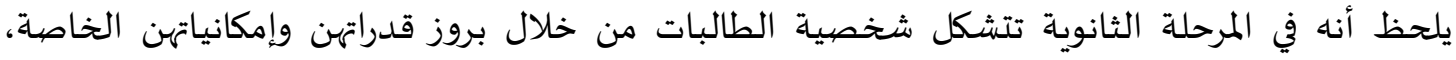

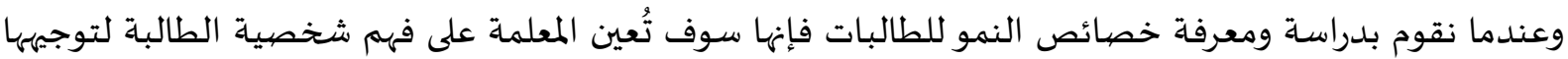
التوجيه السليم الذي يحقق النمو السوي لها. وهي كما جاء بها كل من منصيور والتويجري والفقي

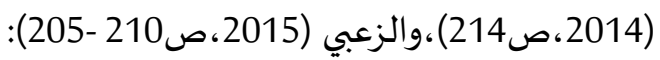

- التغيرات الانفعالية والمزاجية- العلاقات الاجتماعية. - التغيرات الجسمية.- الاستقلالية. - - - الاضطرابات الاجتماعية. - الخصائص الدينية. - - مالخصائص المعرفية العقلية. العلاقة بين كل من مهارات حل المشكلات المستقبلية والتربية المهنية ومهارات اتخاذ القرارات وخصائص نمو

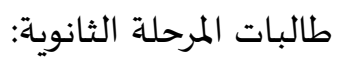
تم اختيار متغير مهارات اتخاذ القرارات ومتغير مهارات حل المشكلات المستقبلية؛ لأنها عندما نريد اتخاذ قرار

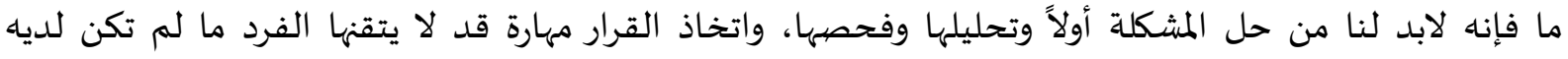

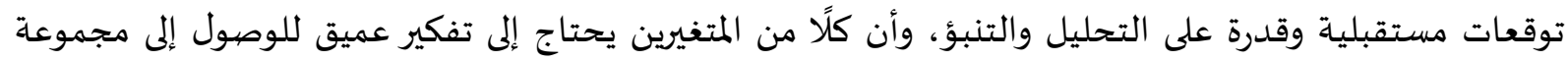

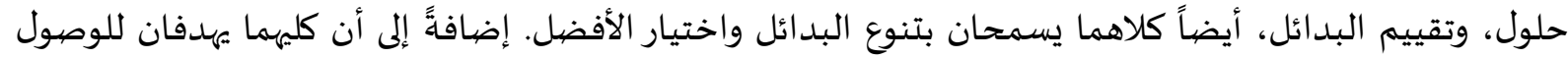

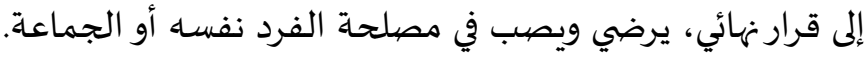

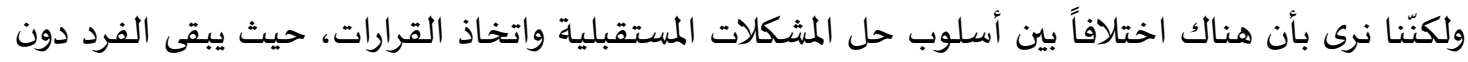

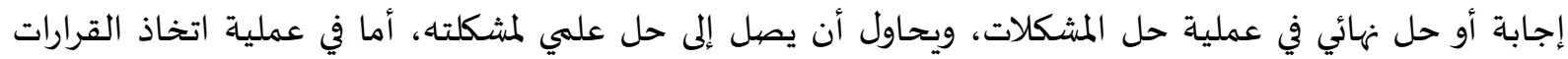

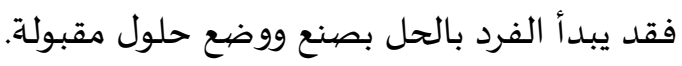

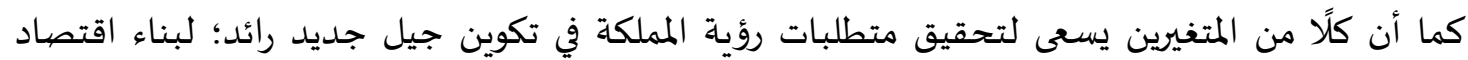

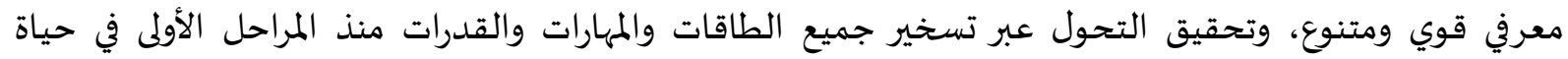

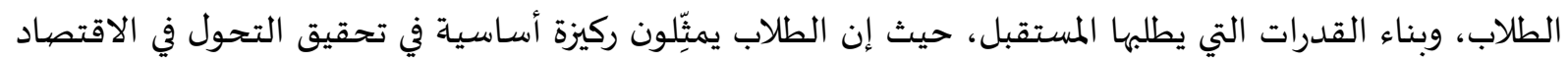

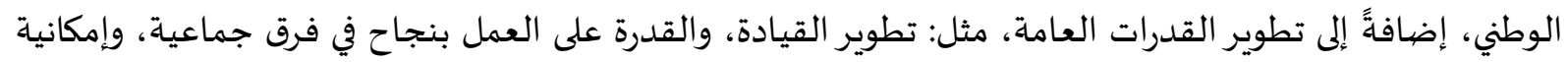

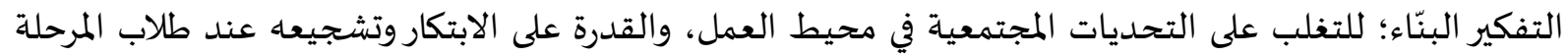

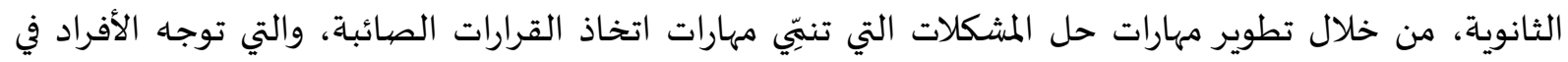

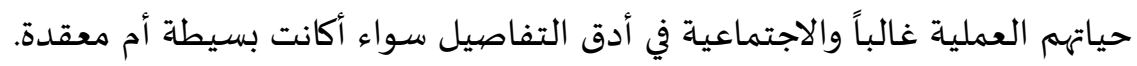


وبناءً على حاجة طلاب وطالبات المرحلة الثانوية للاستقلال في الفكر والرأي، والاعتماد على النفس في

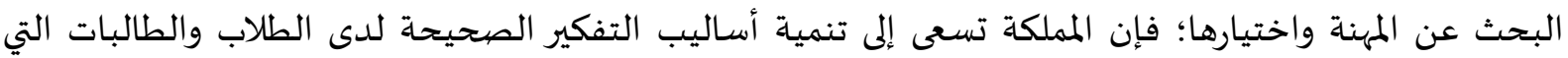

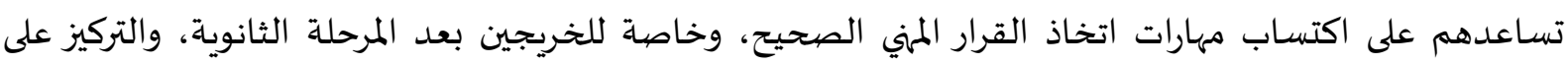

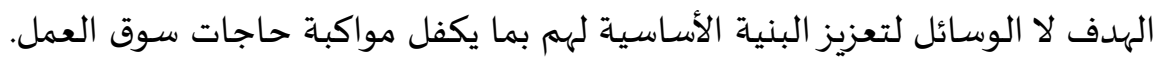

ثانياً- الدراسات السابقة: - هدفت دراسة جريجوري وكليمن (2001) إلى تطوير قدرات الطلبة في اتخاذ القرار. استخدام الباحثان المنهج

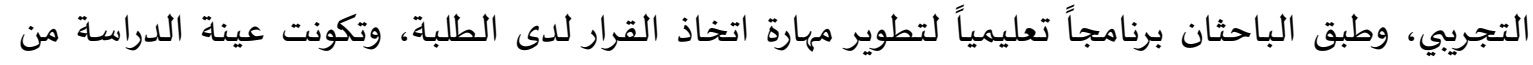

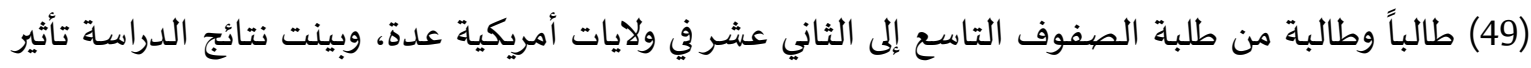
دروس مهارات اتخاذ القرار على أداء الطلبة بشكل إيجابي.

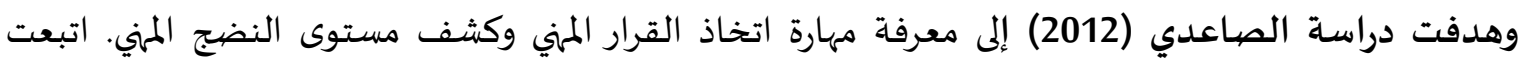

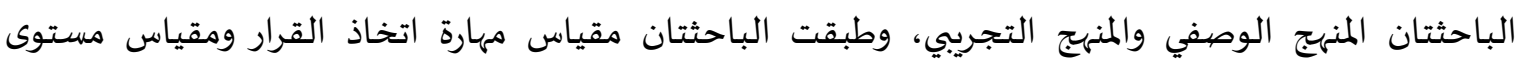

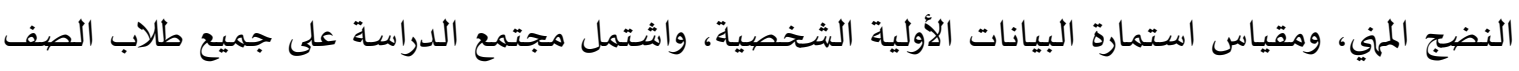

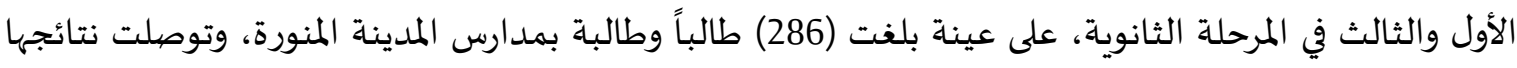

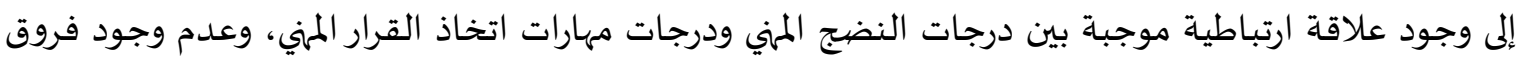

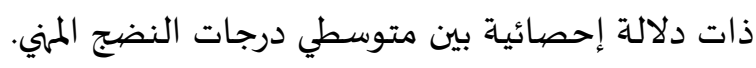

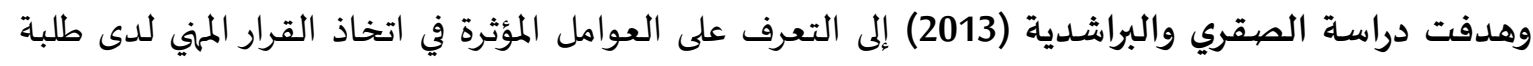

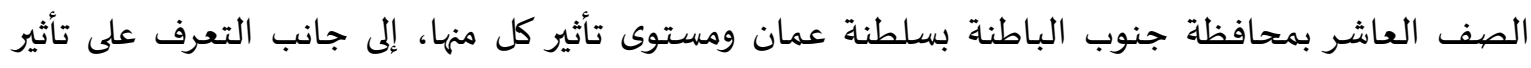

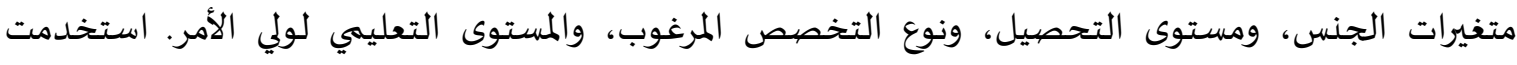

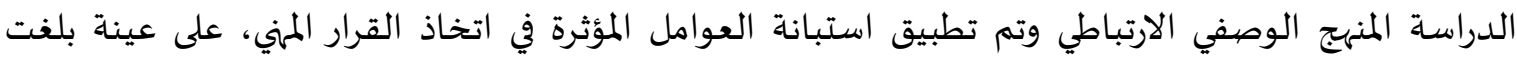

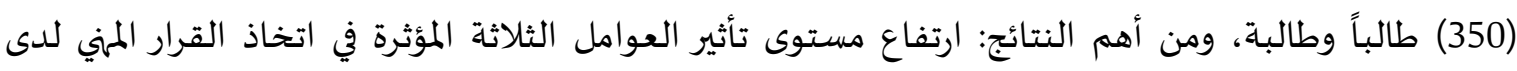

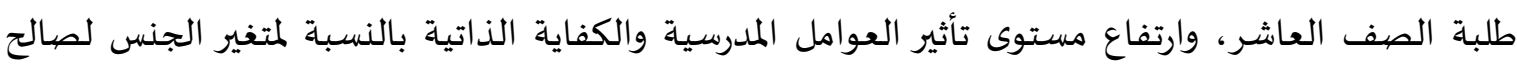

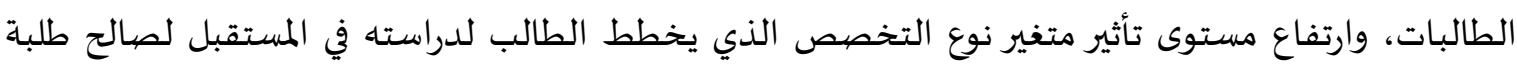
التخصصيات العلمية.

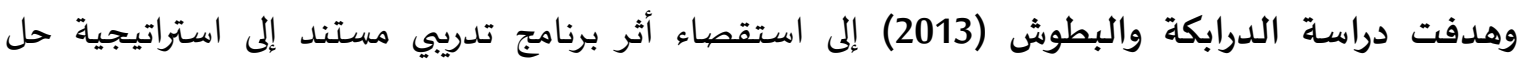

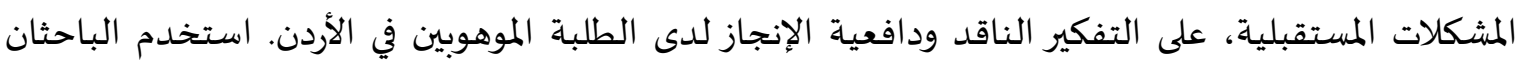

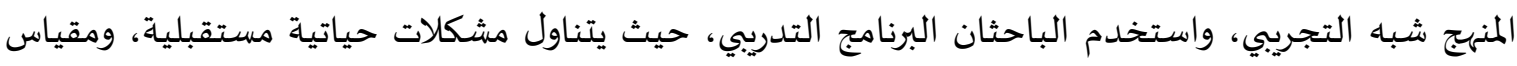

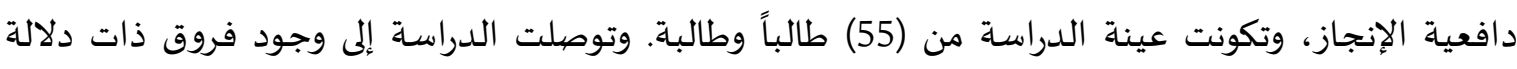
إحصائية تُعزَى لأثر استراتيجية حل المشكلات المستقبلية على جميع مهارات التفكير الناقد وأبعاد دافعية الإنجاز لصالح المجموعة التجريبية. وهدفت دراسة أيوب (2015) إلى قياس أثر برنامج تدريبي قائم على الذكاء العملي في تنمية مهارات ريادة الأعمال

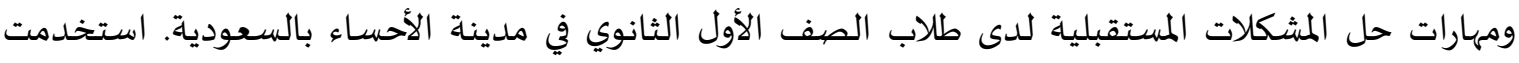

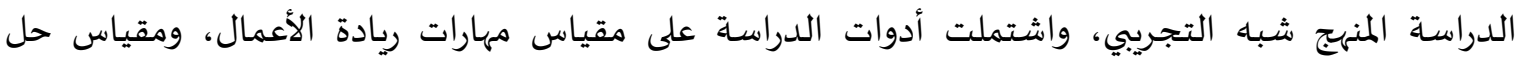

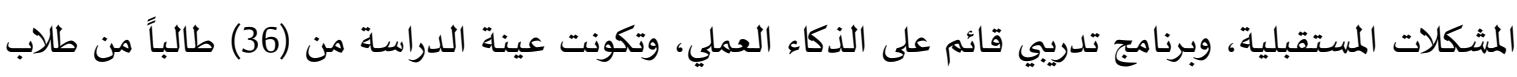

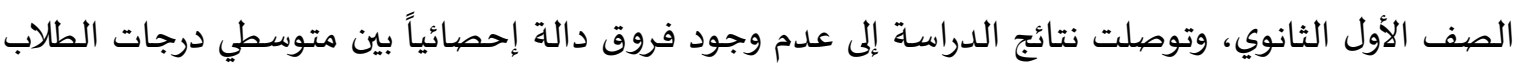


في المجموعتين على أبعاد ريادة الأعمال وحل المشكلات المستقبلية، وإلى فعالية البرنامج في تنمية مهارات ريادة الأعمال وحل المشكلات المستقبلية للطلاب.

وهدفت دراسة عبد الحميد (2015) إلى التعرف على فاعلية استخدام استراتيجية حل المشكلات المستقبلية في

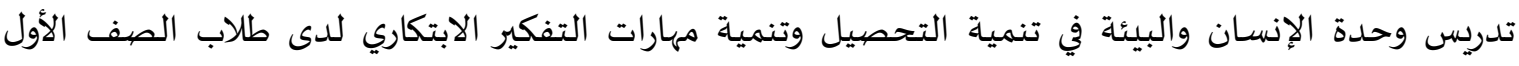

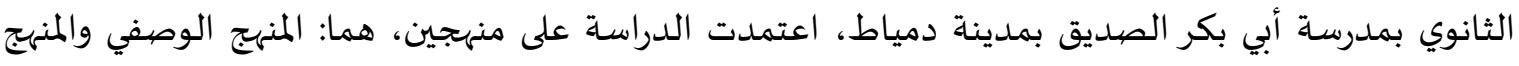

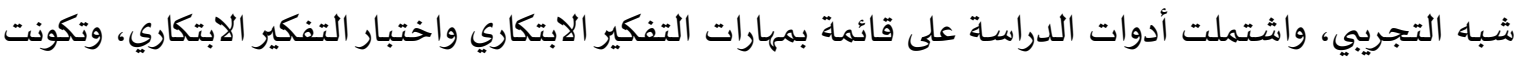

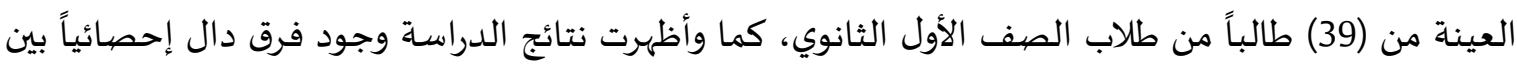

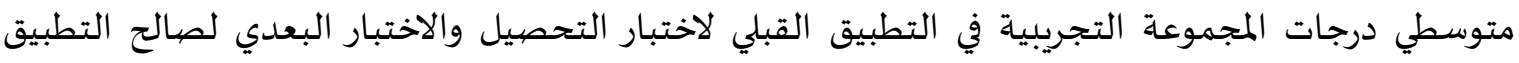

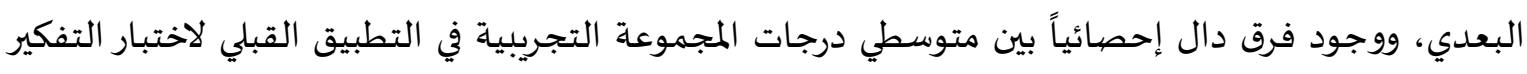
الابتكاري والاختبار البعدي لصالح التطبيق البعدي. وهدفت دراسة المالكي (2016) إلى التوصل لمهارات اتخاذ القرار المناسبة لطلاب وطالبات المرحلة الثانوية واللازم تضمينها في مقرر الثقافة الإسلامية، والكشف عن مدى تضمين مقرر الثقافة الإسلامية للمرحلة الثانوية

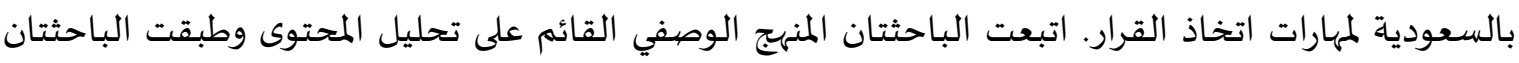

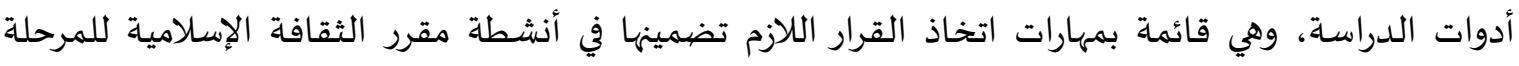

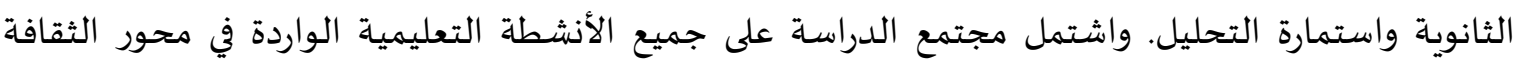

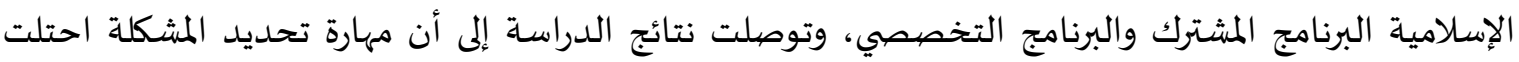

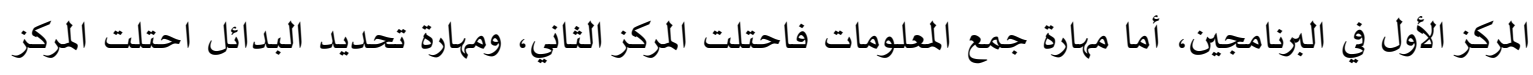

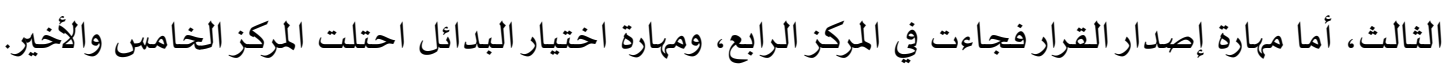

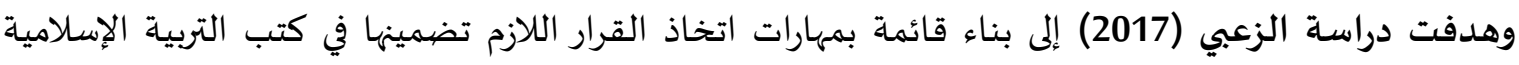

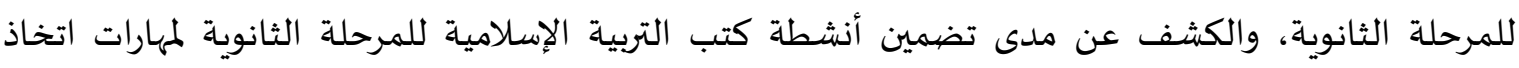

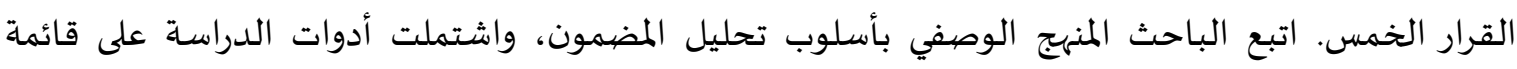

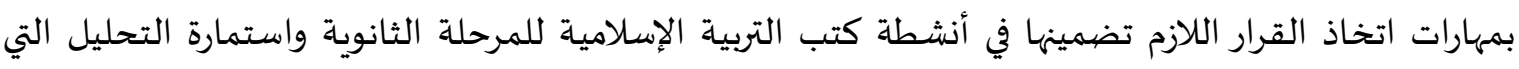

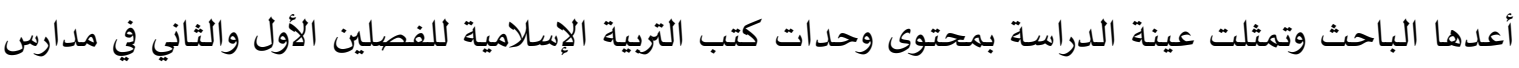

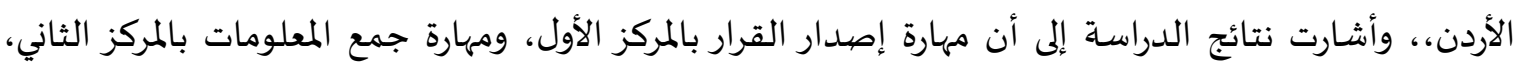

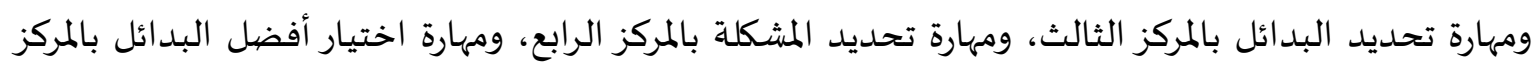
الخامس والأخير. وأخيراً هدفت دراسة علي (2017) إلى التعرف على فعالية برنامج تدريبي قائم على حل المشكلات المستقبلية

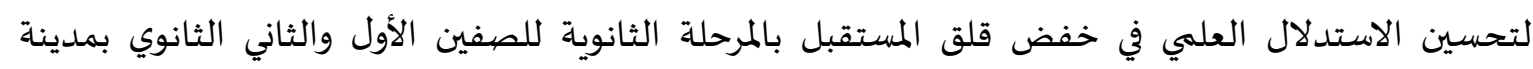

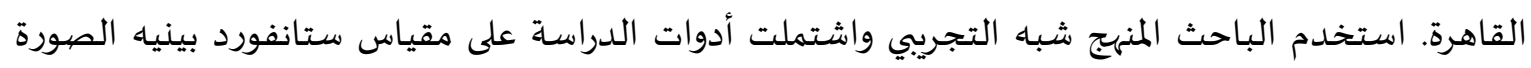

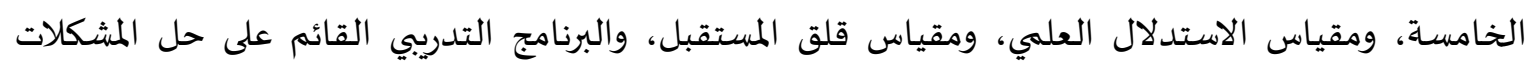

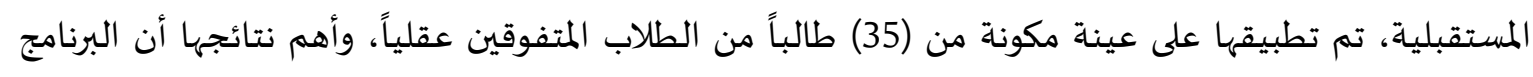

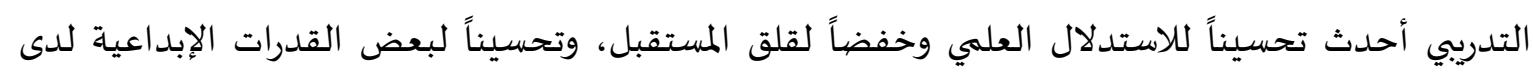
الطلاب المتفوقين عقلياً بالمرحلة الثانوية. 
التعقيب على الدراسات السـابقة:

يتشابه البحث الحالي مع دراسة الصاعدي (2012) وجريجوري وكليمن (2001) في تقصِّي مهارات اتخاذ القرارات، واتفق البحث الحالي مع هذه الدراسات من حيث المرحلة العمرية وأداة البحث، كما واتفقت كل من من وردية

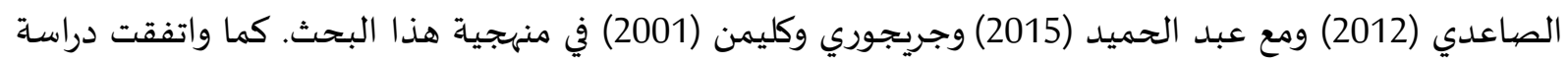

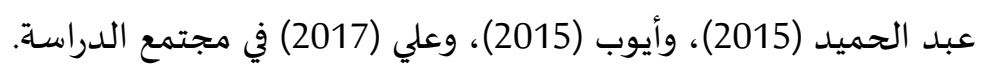

ويختلف هذا البحث عن الدراسات السابقة في تقصِي فاعلية وحدة مقترحة قائمة على مهارات حل

المشكلات المستقبلية في تنمية مهارات اتخاذ القرارات لدى طالبات المرحلة الثانوية الحكومية بمدينة الرياض.

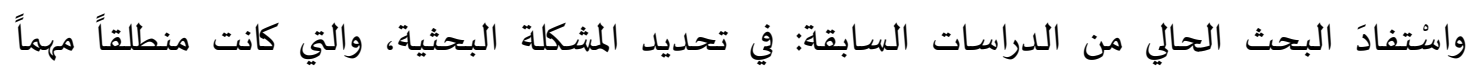

للباحثة، كدراسة المالكي (2016) التي أوصت بالاهتمام بمجال المقررات، ودراسة الصاعدي (2012) في معرفة أهم

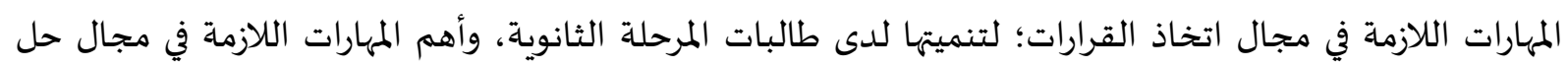

المشكلات المستقبلية؛ والاستفادة من قائمة مهارات حل المشكلات المستقبلية التي جاء بها أيوب (2015).

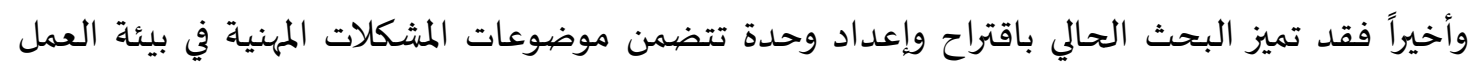

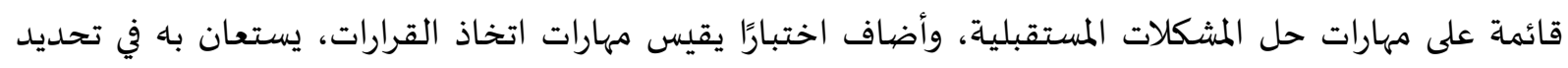

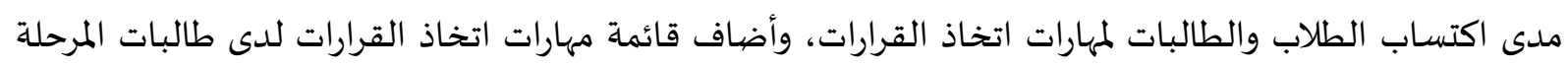
الثانوية.

3- منهبية البحث وإجراءاته.

منهجية البحث:

استخدمت الباحثتان المنهج الوصفي التحليلي لوصف وتحليل الأدبيات والدراسات السابقة ذات الصلة

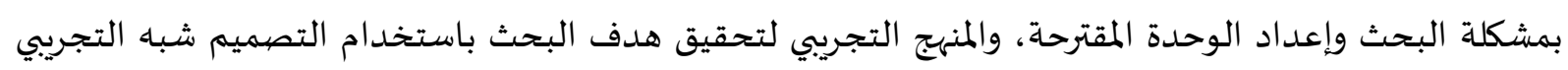
ذو القياس القبلي والبعدي لمجموعتين: إحداهما ضابطة، والأخرى تجريبية.

تكوّن مجتمع البحث من جميع طالبات الصف الثالث الثانوي للمرحلة الثانوية في مدينة الرياض في الفصل الدراسي الأول 1440/1439هـ، وقد بلغ عددهن (24974) طالبة وفقًا لإحصائية إدارة التخطيط والتطوير بمنطقة الرياض للعام الدراسي 1440/1439هـ

عينة البحث: تألفت عينة البحث من: البح:

العينة الاستطلاعية: تم اختيار الصف الثالث الثانوي (أول) بواقع (26) طالبة من المدرسة الثانوية (68) للبنات كعينة استطلاعية، وذلك بالطريقة العشوائية البسيطة، وقد تم تطبيق اختبار مهارات اتخاذ القرارات على الى ملئل هذه العينة؛ بهدف التأكد من صلاحيته، ولمعرفة زمن الاختبار.

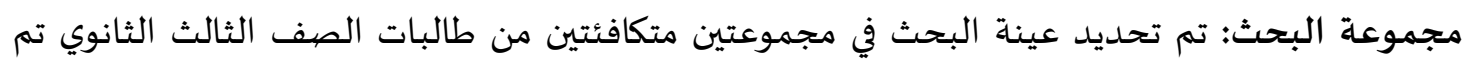
اختيارهن بالطريقة العشوائية العنقودية متعددة المراحل. 


$$
\text { أدوات البحث ومواده: }
$$

أداة البحث: اختبار مهارات اتخاذ القرارات: قامت الباحثتان بإعداد الاختبار مراعية القواعد والمعايير

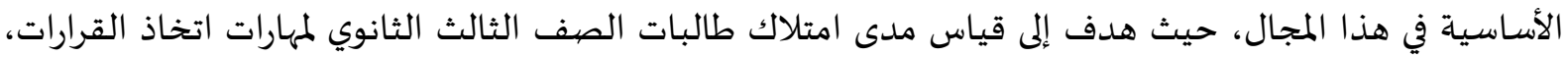

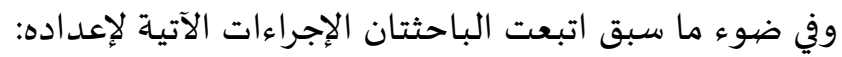

1- تحديد الهدف من الاختبار: تحديد مدى امتلاك طالبات الصف الثالث الثانوي لمهارات اتخاذ القرارات.

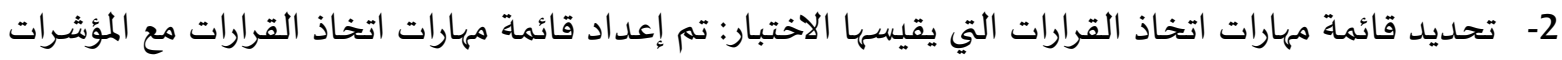

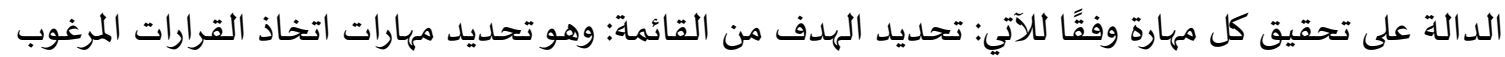

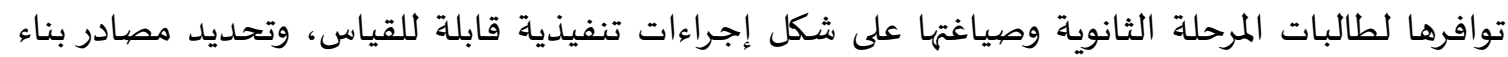
القائمة، وهي: الاطلاع على الأدب التربوي المتعلق باتخاذ القرارات وههاراتها. ومراجعة قوائم مهارات اتخاذ القرارات في البحوث والدراسات التي اهتمت باتخاذ القرارات، ومنها: دراسة الوسيهي (2010)، وعلي (2011)،

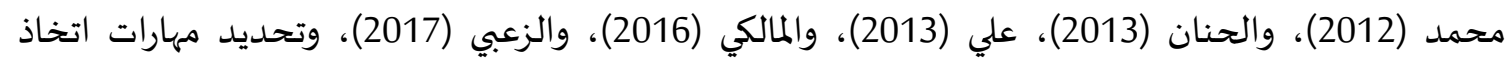

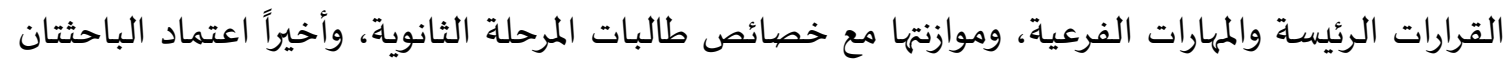

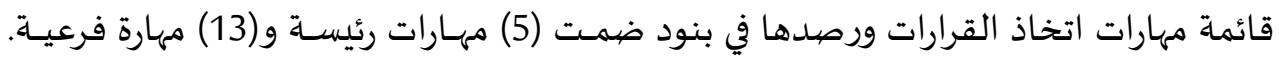

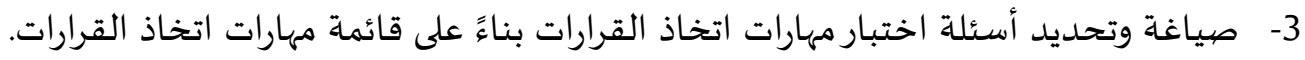

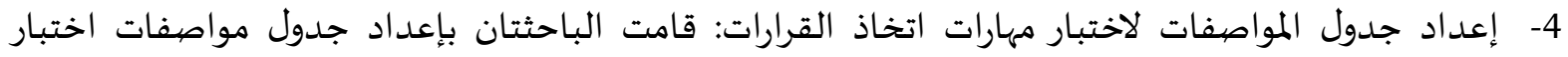
مهارات اتخاذ القرارات؛ ومن خلال الجدول (1) تتضح المواصفات الشاملة لاختبار مهارات اتخاذ القرارات.

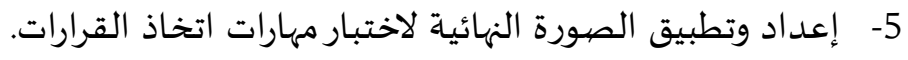
جدول (1) مواصففات اختبار مهارات اتخاذ القرارات

\begin{tabular}{|c|c|c|c|c|c|c|c|c|c|c|c|c|}
\hline \multirow[b]{2}{*}{ 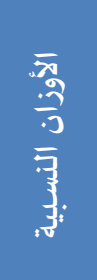 } & \multirow[b]{2}{*}{$\begin{array}{l}\frac{3}{3} \\
\frac{3}{3} \\
\frac{1}{3}\end{array}$} & \multirow[b]{2}{*}{$\begin{array}{l}\frac{3}{3} \\
\frac{3}{3} \\
\frac{3}{3}\end{array}$} & \multicolumn{5}{|c|}{ مهارات اتخاذ القرارات } & \multirow[b]{2}{*}{$\begin{array}{l}\overline{7} \\
\overline{3} \\
\overline{3} \\
\overline{7} \\
\overline{3} \\
\frac{1}{13}\end{array}$} & \multirow[b]{2}{*}{ 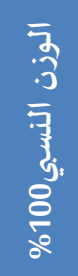 } & \multirow[b]{2}{*}{$\frac{9}{3}$} & \multirow[b]{2}{*}{ المشكلات المهنية في بيئة } & \multirow[b]{2}{*}{$r$} \\
\hline & & & $\frac{\overline{9}}{\frac{7}{3}}$ & 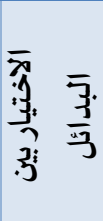 & $\begin{array}{l}\frac{3}{3} \\
\frac{3}{3} \\
\frac{3}{3}\end{array}$ & $\frac{1}{3}$ & 等 & & & & & \\
\hline \multirow{2}{*}{ \%16.7 } & \multirow{2}{*}{5} & \multirow{2}{*}{5} & 0 & $\mathbf{0}$ & $\mathbf{0}$ & 3 & 2 & الفقرات & \multirow{2}{*}{$\% 40$} & \multirow{2}{*}{2} & \multirow{2}{*}{ المشكلات المهنية مع } & \multirow{2}{*}{1} \\
\hline & & & 0 & $\mathbf{0}$ & $\mathbf{0}$ & 3 & 2 & الدرجة & & & & \\
\hline \multirow{2}{*}{ \%16.7 } & \multirow{2}{*}{7} & \multirow{2}{*}{5} & 0 & $\mathbf{0}$ & 3 & 1 & 1 & الفقرات & \multirow{2}{*}{$\% 20$} & \multirow{2}{*}{1} & \multirow{2}{*}{ زمشكلات المهنية مع المعل } & \multirow{2}{*}{2} \\
\hline & & & 0 & $\mathbf{0}$ & 4 & 2 & 1 & الدرجة & & & & \\
\hline \multirow{2}{*}{$\% 30$} & \multirow{2}{*}{9} & \multirow{2}{*}{9} & 0 & 2 & 4 & 2 & 1 & الفقرات & \multirow{2}{*}{$\% 20$} & \multirow{2}{*}{1} & \multirow{2}{*}{ المشكلات المهنية } & \multirow{2}{*}{3} \\
\hline & & & 0 & 2 & 4 & 2 & 1 & الدرجة & & & & \\
\hline \multirow{4}{*}{$\% 36.6$} & \multirow[b]{2}{*}{11} & \multirow[b]{2}{*}{11} & 2 & 3 & 3 & 2 & 1 & الفقرات & \multirow[b]{2}{*}{$\% 20$} & \multirow[b]{2}{*}{1} & \multirow{2}{*}{ والتطوير الإداري في بيئة الإنتاج } & \\
\hline & & & 2 & 3 & 3 & 2 & 1 & الدرجة & & & & 4 \\
\hline & & & 30 & 2 & 5 & 10 & 8 & 5 & & & موع الفقرات الرئيسية والف & \\
\hline & رجة & & & 2 & 5 & 11 & 9 & 5 & & & مجموع الدرجات & \\
\hline$\% 100$ & & & & $\% 6.7$ & \%16.7 & $\% 33.3$ & $\% 26.6$ & \%16.7 & & & الأوزان النسبية للمهـ & \\
\hline
\end{tabular}




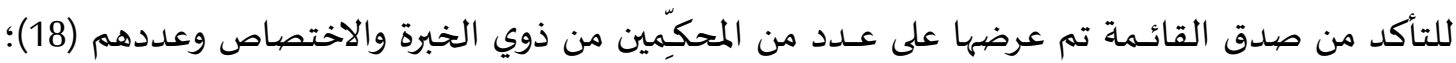

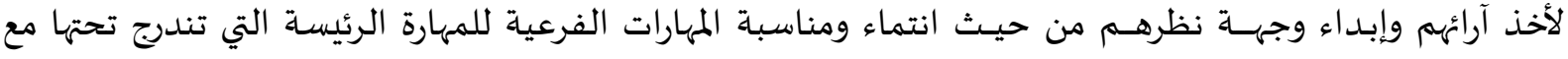
إتاحة الفرصة لهم بالإضافة أو التعديل على القائمة. وبعد ذلك تم القيام بعملية الضبط الإحصائي لاختبار مهارات اتخاذ القرارات من خلال ما يأتي: 1- الصدق الظاهري (صدق المحتوى): وللتأكد من الصدات الظاهري للاختبار تم عرضها على مجموعاة من

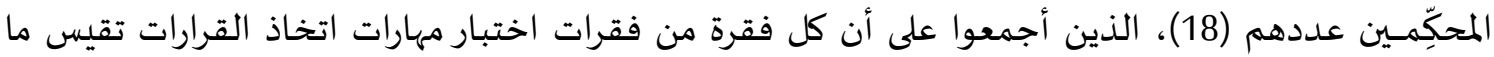

$$
\text { وضعت لقياسه. }
$$

2- - صدق الاتساق الداخلي لفقرات الاختبار حيث تم حساب معاملات الارتباط بين درجة كل سؤال من أسئلة الاختبار والدرجة الكلية له؛ للتأكد من تماسك الأسئلة بالدرجة الكلية للمحور الذي تنتمي إليه باستخدام معامل بيرسون.

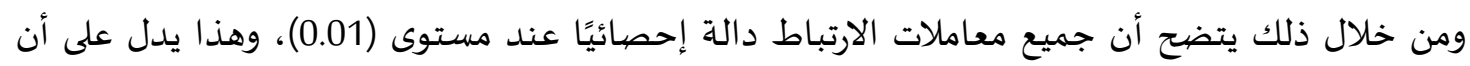

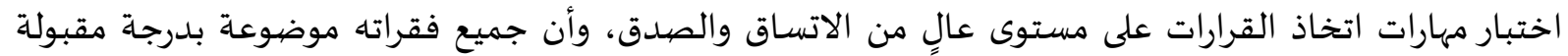

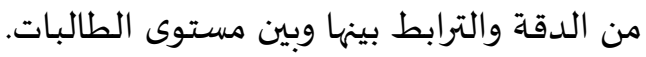
3- حساب ثبات الاختبار: تم رصد الدرجات وتفريغها في جداول؛ لاستخداتها فيا في حساب معاملات الثبات، حيث تم

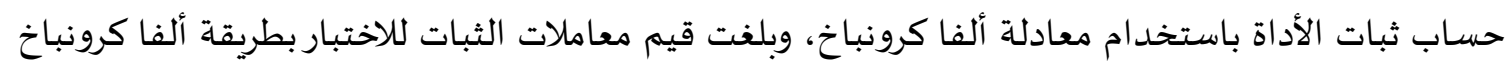

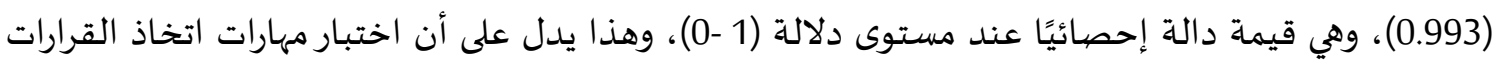
يتمتع بدرجة عالية من الثبات. واستخدام اختبار "ت" Test: للتأكد من تكافؤ مجموعتي البحث في كل من: (العمر، التحصيل في التربية المهنية)، ولحساب الفرق بين متوسطي درجات الطالبات للمجموعتين التجريبية والضابطة في اختبار مهارات اتخاذ القرارات.

4- حساب معامل السهولة والصعوبة والتمييز للاختبار: تراوحت معاملات الصعوبة للاختبار بين (0.65 -0.35)، وهذا يدل على أن اختبار مهارات اتخاذ القرارات معتدل الصعوبة، بينما تراوحت معاملات السهولة لهولة للاختبار

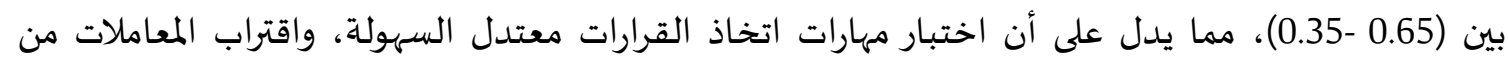

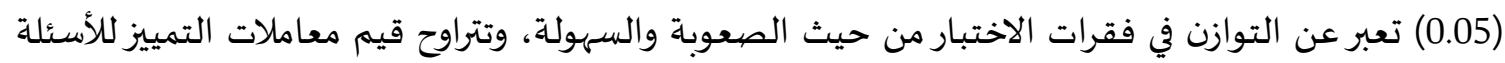

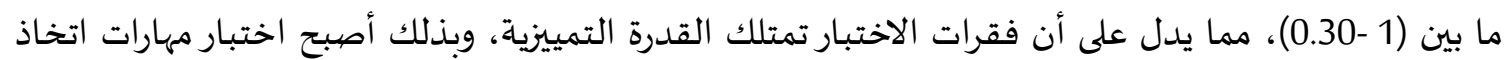
القرارات جاهزًا للتطبيق. 5- حساب زمن الاختبار: الزمن= (70+70+75+75+75)+(25+95+95+100+100)/ 10=(85) دقيقة. وتم إضافة (5) دقائق لتنظيم الطالبات وتوزيع أوراق اختبار مهارات اتخاذ القرارات وقراءة التعليمات،

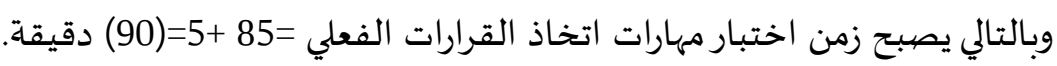

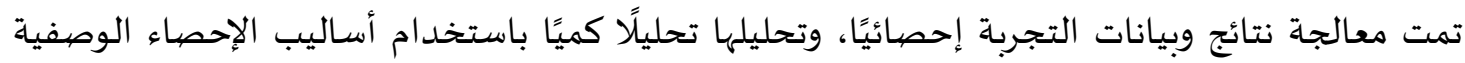
الكمية، بالتعاون مع أحد المحللين الإحصائيين بواسطة برنامج الرزم الإحصائية (SPSS).

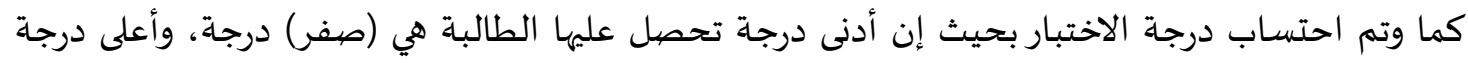

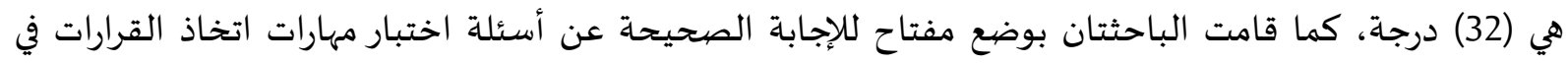

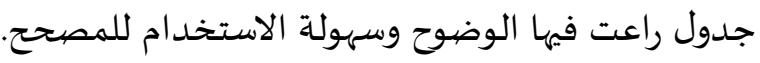


أ- تصهيم وبناء الوحدة المقترحة القائمة على مهارات حل المشكلات المستقبلية:

$$
\text { 1- - تحديد مبررات تصميم وبناء الوحدة المقترحة. }
$$

2- تحديد مهارات حل المشكلات المستقبلية: استفادت الباحثتان من قائمة مهارات حل المشكلات المستقبلية المعدة

$$
\text { في دراسة أيوب (2015)، وهذه المهارات هي: }
$$

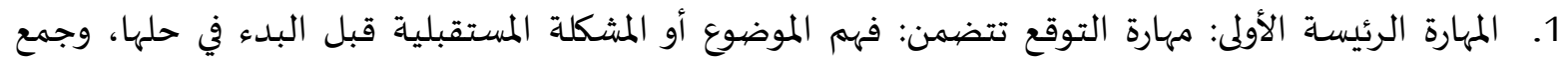

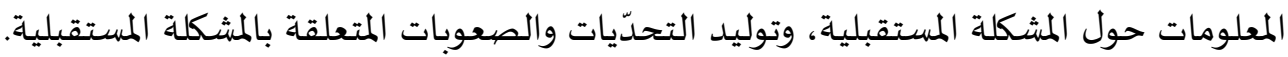

2. المهارة الرئيسة الثانية: مهارة التصور تتضمن: تحديد المشكلة المستقبلية الأساسية من بين مجموعاة من

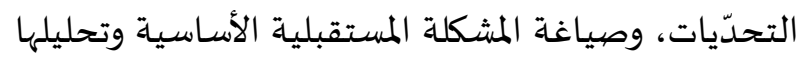

3. المهارة الرئيسة الثالثة: مهارة التخطيط تتضمن: توليد أكبر قدر ممكن من الأفكار والحلول لحل المشكلة

المستقبلية، وتحديد الوقت المناسب لحل المشكلة المستقبلية.

4. المهارة الرئيسة الرابعة: مهارة التنبؤ تتضيمن: تكوين صورة مستقبلية عن الموضوع والمشكلة المستقبلية، وتوليد

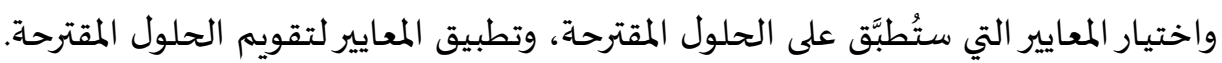

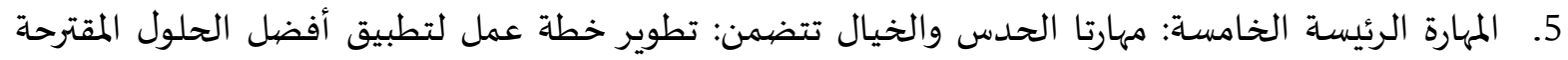

للمشكلة المستقبلية، وتطوير خطة عمل للحل المقترح من خلال إظهار أهمية الحل للمشكلة المستقبلية. وتعزو الباحثتان اختيارها قائمة مهارات حل المشكلات المستقبلية المحكمة مسبقًا في دراسة أيولة ألماب (2015)

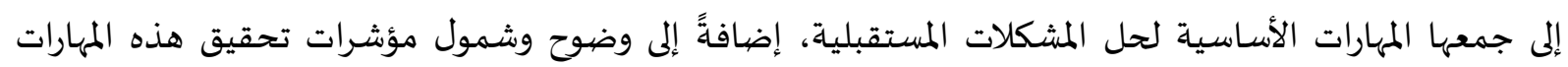
الأساسية وإمكانية تطبيقها. 3- تحديد أهداف الوحدة المقترحة.

4- تحديد محتوى الوحدة المقترحة وتنظيمها. 5- تحديد الأنشطة واستراتيجيات التدريس في الوحدة. 6- تحديد التقنيات والوسائل المستخدمة. 7- تحديد أسـاليب تقويم الوحدة المقترحة. ب- إعداد دليل المعلمة للوحدة المقترحة. ج- ضبط الوحدة المقترحة ودليل المعلمة.

\section{4- عرض نتائج البحث ومناقشتها.}

الإجابة عن سؤال البحث: "ما فاعلية وحدة مقترحة قائمة على مهارات حل المشكلات المستقبلية في تنمية

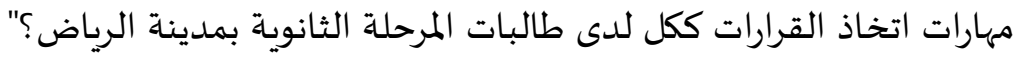

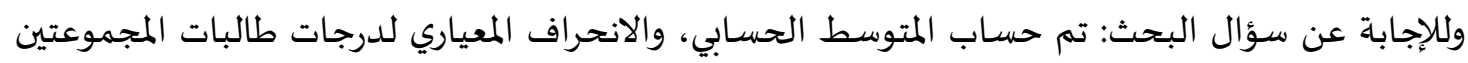

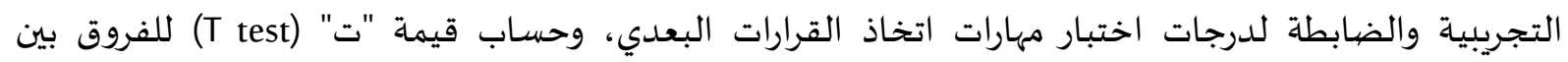
المتوسطات، ومعامل مربع إيتا لقياس حجم الأثر، ومعامل بليك لحساب نسبة الكسب المعدل؛ للتحقق من فاعلية

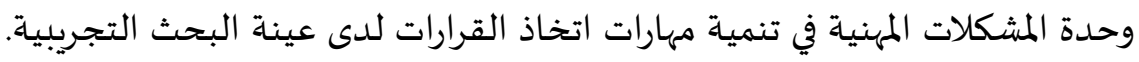


جدول (2) اختبار "ت" Test لبيان الفروق الإحصائية بين المجموعة التجريبية والمجموعة الضيابطة في الاختبار البعدي لمهارات اتخاذ القرارات ككل الِحليان

\begin{tabular}{|c|c|c|c|c|c|c|c|c|}
\hline المعسب المعدل بليك & مربع & الإحصبائية الدلاية & قيمة "ت" & الحرية & الالنحراف & المتوسط الحسابي & المجموعة & المهارة \\
\hline \multirow{2}{*}{1.51} & \multirow{2}{*}{0.929} & \multirow{2}{*}{${ }^{*} 0.00$} & \multirow{2}{*}{12.48} & \multirow{2}{*}{59} & 0.434 & 4.86 & التجريبية & \multirow{2}{*}{ تحديد } \\
\hline & & & & & 1.15 & 2.06 & الضيابطة & \\
\hline \multirow{2}{*}{1.21} & \multirow{2}{*}{0.958} & \multirow{2}{*}{$*_{0}^{*} 00$} & \multirow{2}{*}{9.77} & \multirow{2}{*}{59} & 2.25 & 13.71 & التجريبية & \multirow{2}{*}{ المعلومات } \\
\hline & & & & & 3.23 & 6.70 & الضابطة & \\
\hline \multirow{2}{*}{1.20} & \multirow{2}{*}{0.885} & \multirow{2}{*}{$*_{0} 0.00$} & \multirow{2}{*}{9.29} & \multirow{2}{*}{59} & 1.75 & 10.80 & التجريبية & \multirow{2}{*}{ تحديد البدائل } \\
\hline & & & & & 2.89 & 5.08 & الضيابطة & \\
\hline \multirow{2}{*}{1.52} & \multirow{2}{*}{0.952} & \multirow{2}{*}{$* 0.00$} & \multirow{2}{*}{13.40} & \multirow{2}{*}{59} & 0.379 & 4.83 & التجريبية & \multirow{2}{*}{ الاختيار بين } \\
\hline & & & & & 1.11 & 1.96 & الضابطة & \\
\hline \multirow{2}{*}{1.48} & \multirow{2}{*}{0.778} & \multirow{2}{*}{$*_{0} 0.00$} & \multirow{2}{*}{8.41} & \multirow{2}{*}{59} & 0.305 & 1.90 & التجريبية & \multirow{2}{*}{ إصددار القرار } \\
\hline & & & & & 0.668 & 0.77 & الضابطة & \\
\hline \multirow[b]{2}{*}{1.32} & \multirow[b]{2}{*}{0.967} & \multirow[b]{2}{*}{${ }^{*} 0.00$} & \multirow[b]{2}{*}{15.66} & \multirow[b]{2}{*}{59} & 3.33 & 28.7 & التجريبية & \multirow{2}{*}{ كهارات } \\
\hline & & & & & 4.41 & 13.05 & الضابطة & \\
\hline
\end{tabular}

ويتضح من الجدول (2) بأنه يوجد فرق ذو دلالة إحصائية بين المجموعة التجريبية والمجموعة الضابطة في

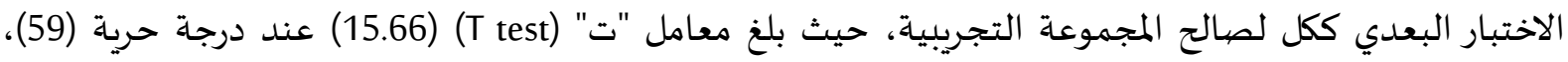

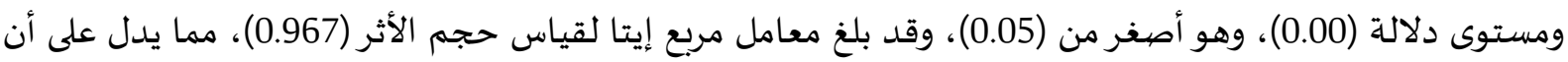

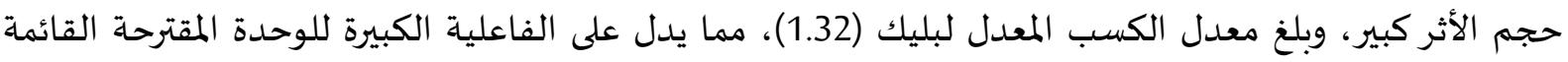

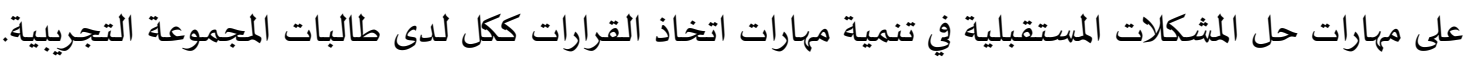

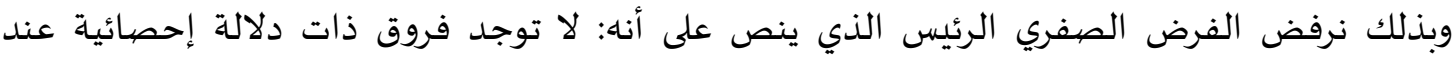

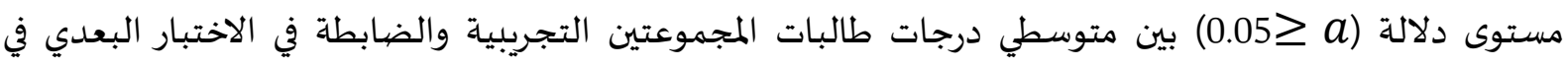

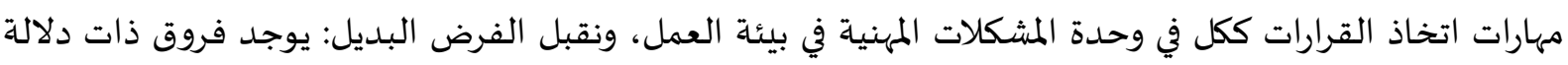
إحصائية عند مستوى دلالة (0.05 ) بين متوسطي درجات طالبات المجموعتين التجريبية والضابطة في الاختبار

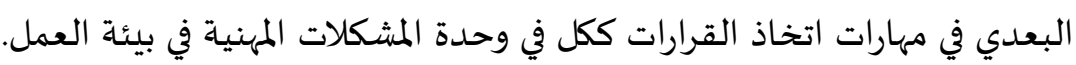

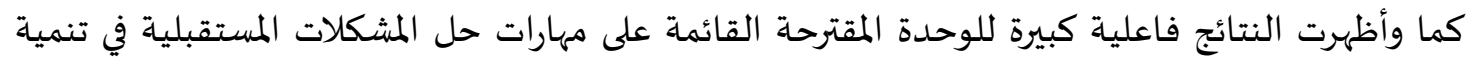

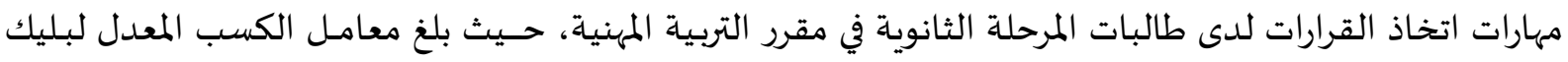

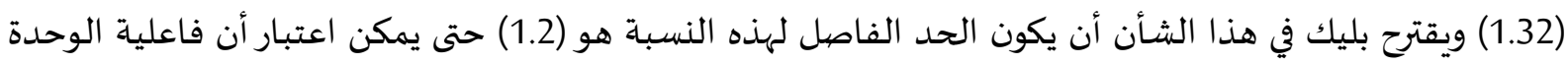
مقبولة، وتظهر نتيجة ذلك من خلال تفوق المجموعة التجريبية على المجموعة الضابطة في اختبار مهارات اتخاذ 
إن وجود فروق ذات دلالة إحصائية بين طالبات المجموعة التجريبية والتقليدية، تعكس مدى فاعلية وحدة المشكلات المهنية في بيئة العمل القائمة على مهارات حل المشكلات المستقبلية في إكساب الطالبات دلات مهارات اتخاذ

كما واتفقت نتائج دراسة الصاعدي (2012) ودراسة الصقري والبراشدية (2013) وجريجوري وكليمن (2001)، على تحقق أهدافها في تحسين قدرة الطلاب والطالبات على اتخاذ القرار، وعلى أهمية النضج بأنواعه؛؛

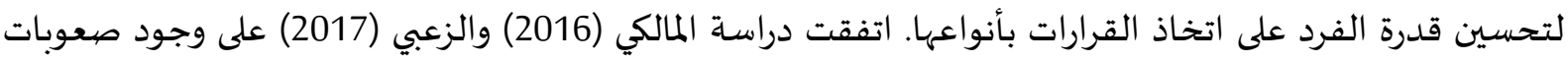
في اتخاذ القرار عند الطلاب والطالبات، مما يؤكد ذلك على الحاجة لتدريب الطلاب والطالبات وإكسابهم مهارات اتخاذ القرار في جوانب حياتهم المختلفة. اتفقت نتائج دراسة الدرابكة والبطوش (2013)، وعبد الحميد (2015)،

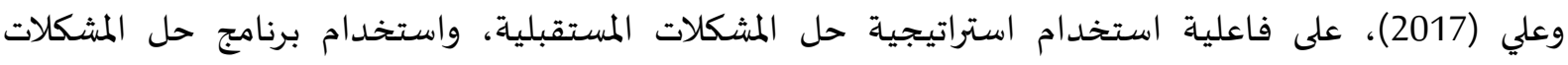

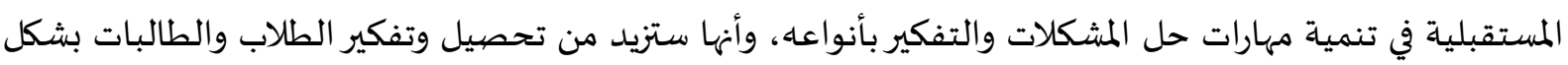
أفضل من الطريقة التقليدية. وهذه النتائج سواء كانت في الدرجة الكلية للاختبار أو الدرجات الفرعية تشير إلى أن للوحدة المقترحة القائمة

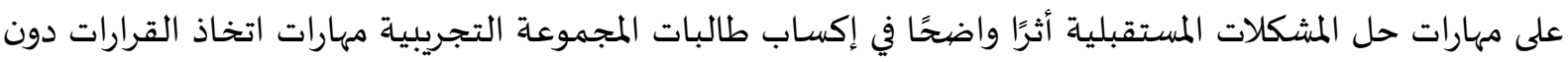
الضابطة، وتتفق هذه النتيجة مع دراسة علي (2017) التي توصلت إلى أن للبرنامج القائم على حل المشكات المكلات

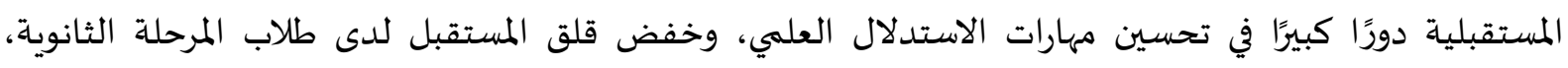

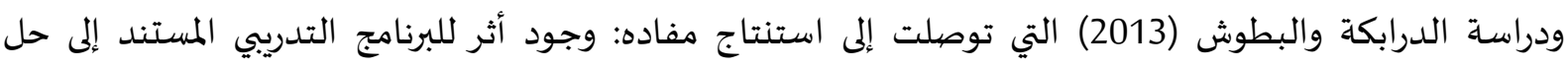

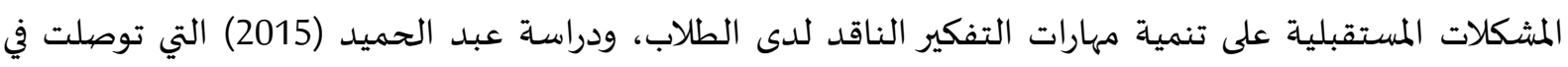
نتائجها إلى تحقيق استراتيجية حل المشكلات المستقبلية فاعلية كبيرة في تنمية مهارات التفكير الابتكاري.

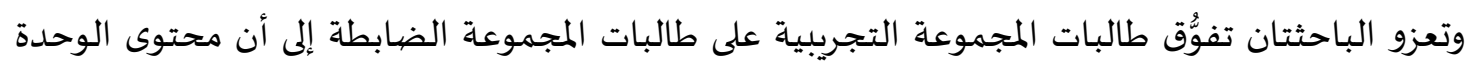

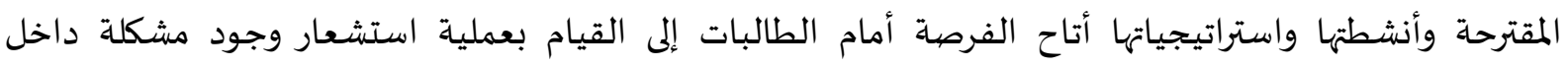

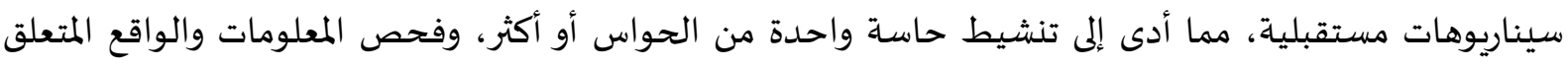

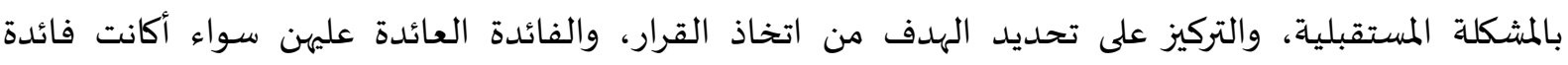
شخصية أم لمصلحة الجميع. كما وأتاح محتوى الوحدة التعليمية المقترحة وأنشطتها واستراتيجياتها الفرصة أمام الطالبات إلى امتلاك معارف ومعلومات تستند إلى حقائق وأدلة، كذلك قدرتهن على تحديد المشكلة المستقبلية، وتشكيل المفهوم ساعداتهن

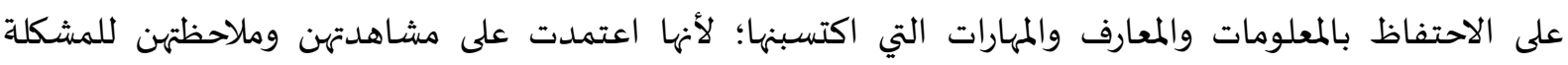

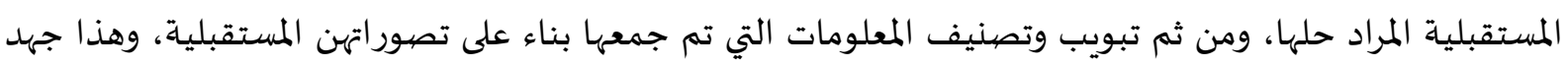

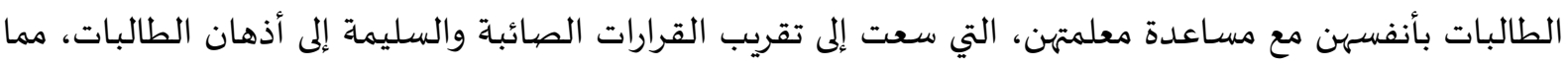

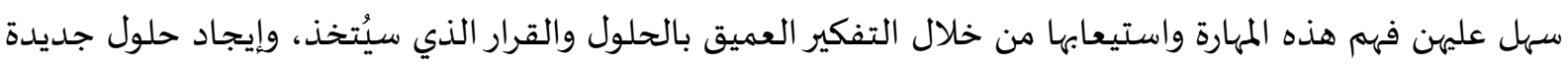

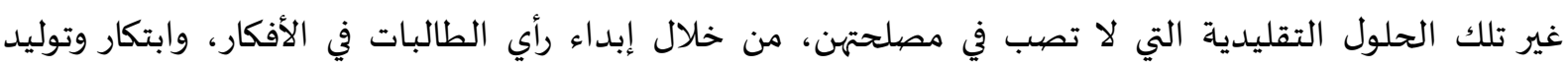

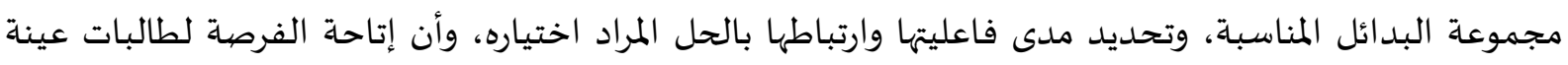

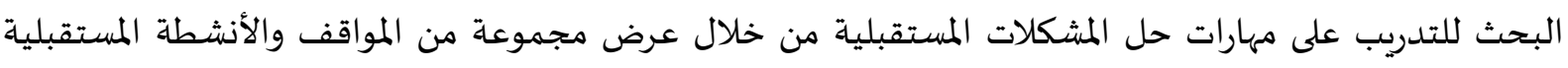

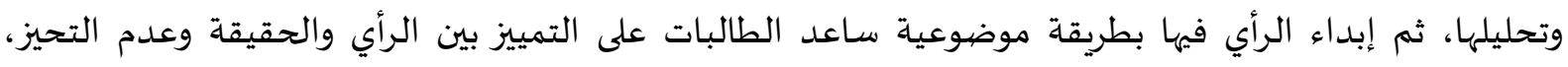

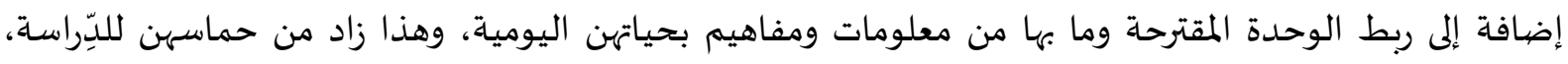
والشعور بأهمية موضوعات الوحدة بالنسبة لهن، مما انعكس على مستوى تفكيرهن، ومن هنا حرصت البهات الباحثتان في 


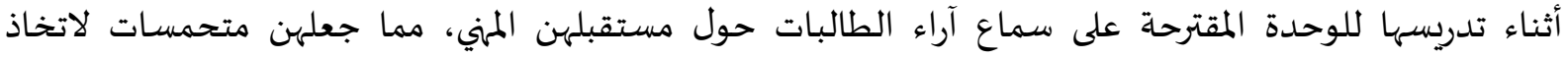

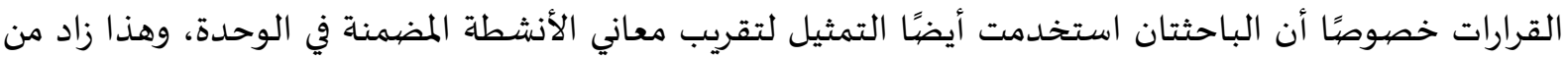

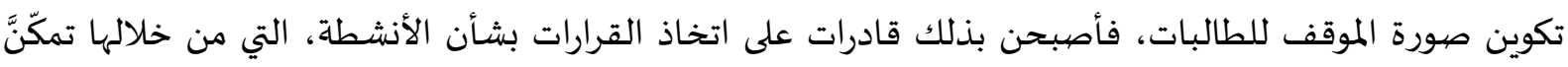

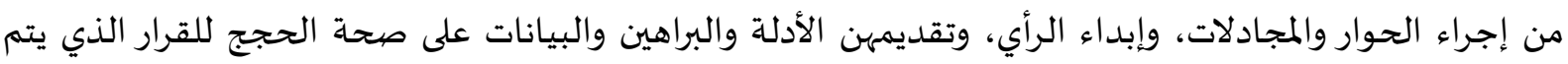

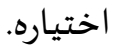

وربما يعود نجاح الوحدة المقترحة القائمة على مهارات حل المشكلات المستقبلية وفاعليتها في تنمية مهارات اتخاذ القرارات لدى طالبات المجموعة التجريبية باختلاف المستوى العقلي للأمور التالية:

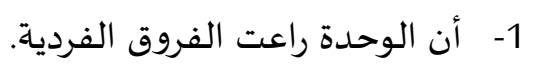

2- تأثير المتغير المستقل: حيث تمتاز مهارات حل المشكلات المستقبلية بجعل بيئة الموقف التعليمي غنية

$$
\text { بمتغيرات مهارات اتخاذ القرارات. }
$$

3- استخدام الباحثتان لاستراتيجيات تدريس تهتم بالناحية النقدية والإبداعية، مثل: استراتيجية حل المشكلات

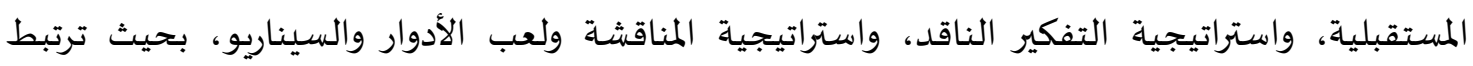

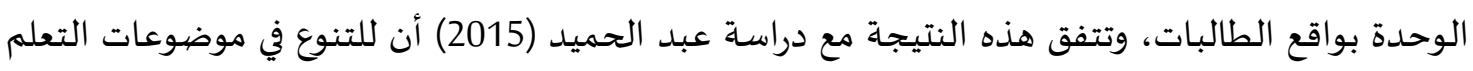
واستخدام استراتيجيات تهدف إلى تنمية مهارات حل المشكلات المستقبلية أثر كبير في تنمية التحصيل والتفكير الابتكاري للطلاب والطالبات. كما وتفسّر الباحثتان ظهور النتائج السابقة في أن جانب المعلومات الخارية لماتية بمهارات اتخاذ القرارات تتطلب

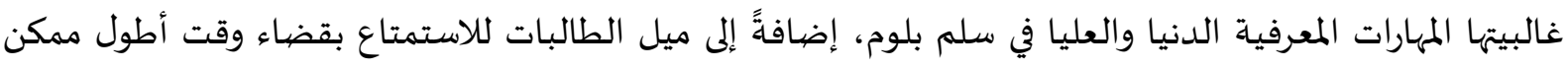

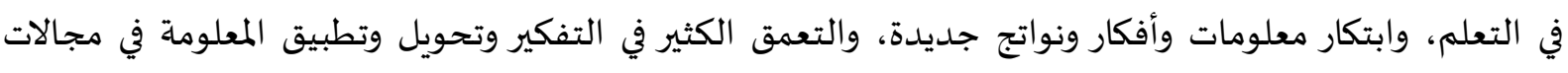

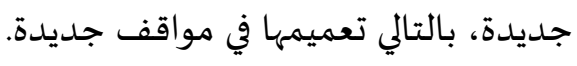
وأن اهتمام الباحثتان بالتسلسل في إكساب الطالبات مهارات حل المشكلات المستقبلية بطرح عدد من

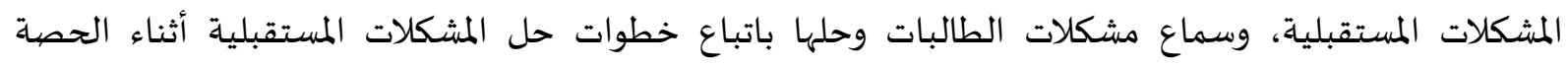
الدراسية أدى إلى إكساب الطالبات مهارات اتخاذ القرار.

$$
\text { توصيات البحث ومقترحاته. }
$$

استنادا إلى نتائج البحث توصي الباحثتان وتقترحان ما يلي:

1- - توجيه مسؤولي المناهج في وزارة التعليم للاهتمام بتنمية مهارات حل المشكلات المستقبلية، من خلانيات خلال المنهج الدراسي. 2- الاستفادة من مرونة مقرر التربية المهنية في تحقيق أهداف مستقبلية تساعد الطلاب والطالبات على تحديد

$$
\text { مساراتهم المهنياة. }
$$

3- الاستفادة من الوحدة المقترحة القائمة على مهارات حل المشكلات المستقبلية، والتي أعدتها الباحثتان؛ لتنمية

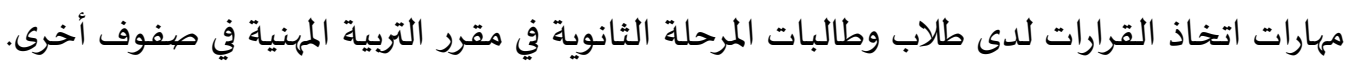

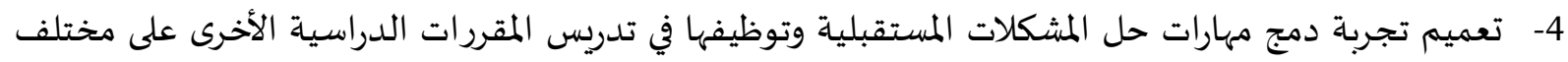

$$
\text { المراحل الدراسية. }
$$

5- أن تهتم الجامعات والكليات حاليًا ومستقبلًا بتدريب الطلاب والطالبات الجامعيين على اكتساب مهارات اتخاذ

$$
\text { القرارات المهنية والعملية. }
$$


6- بناء وحدات مشابهة؛ لتنمية قدرات الطلاب والطالبات نحو اتخاذ القرارات في مراحل مبكرة؛ كالمرحلة المتوسطة والابتدائية من التعليم العام.

7- كما تقترح الباحثتان القيام بإجراء دراسات مكملة للبحث الحالي تركز على دور معلمات التربية المهنية في تنمية

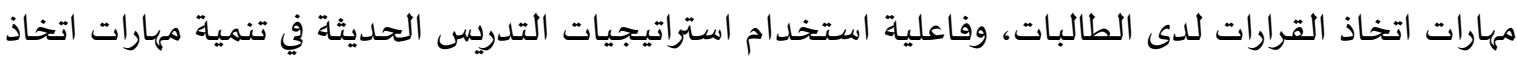

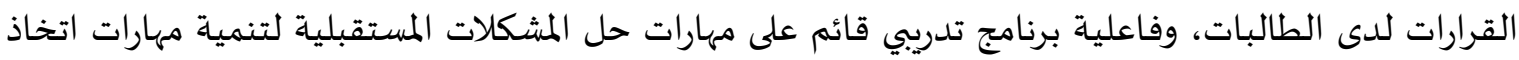

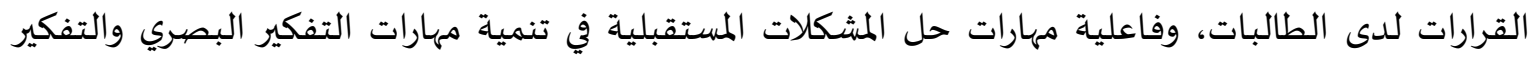

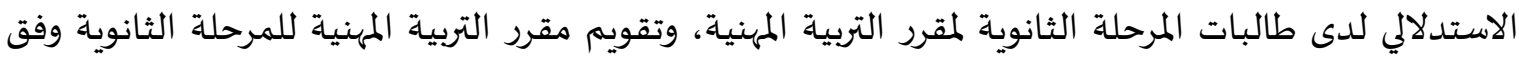
مهارات اتخاذ القرارات المهنية.

\section{مراجع البـحث.}

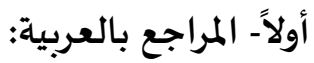

- أبو صفية، لينا. (2010). فاعلية برنامج تدريسي مستند إلى حل المشكلات المستقبلية في تنمية التفكير المستقبلي لدى عينة من طالبات الصف العاشر في الزرقاء. رسالة دكتوراه، الجامعة الأردنية، الأردن.

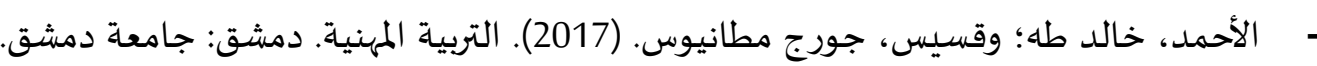
- الأغا، عاطف. (2016). الذكاء الانفعالي وعلاقته بالقدرة على حل المشكلة لدى عينات من المراهقين. رسالة ماجستير. الجامعة الإسلامية، غزة. أيوب، علاء الدين. (2015). فعالية برنامج قائم على الذكاء العملي في تنمية مهارات ريادة الأعمال وحل المشكلات الماتهات

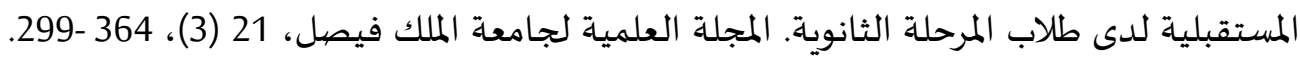
- البخاري، محمد. (2014). حل المشكلات المستقبلية الإبداعية للطالب الثانوي العادي والموهوب في المملكة

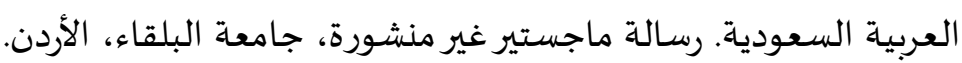

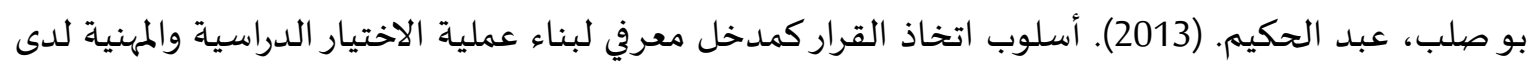
تلاميذ المرحلة الثانوية. مجلة العلوم الإنسانية، (40)، 490 -465. جامعة الملك سعود. (2018). المؤتمر الثامن عشر للجمعية السعودية للعلوم التربوية والنفسية: التعليم ما بعد المدانية (40)، الثانوي والهوية ومتطلبات التنمية 15 -14 مارس

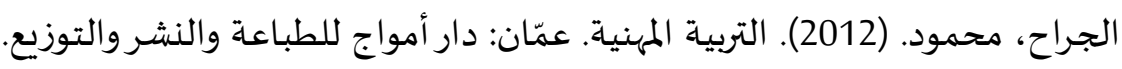

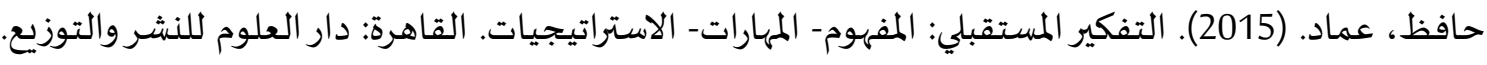

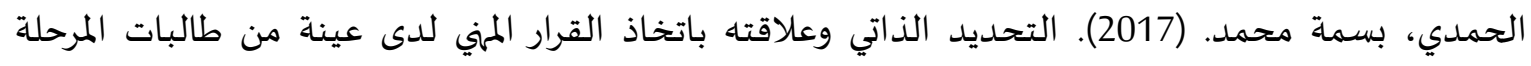
الثانوية في جدة. رسالة ماجستير، جامعة الملك عبد العزيز، المملكة العربية السعودياة.

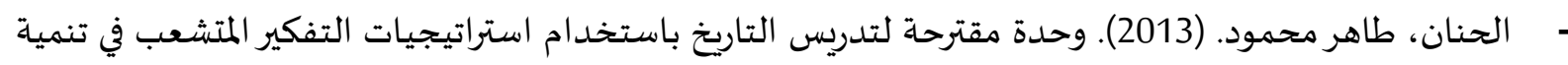

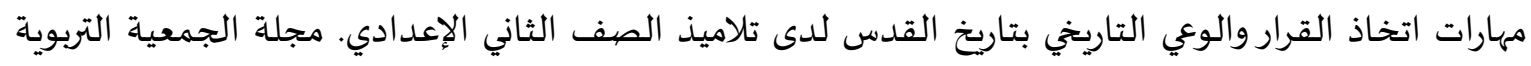
للدراسات الاجتماعية، (48)، 75 -13. - دخل الله، أيوب. (2015). التربية ومشكلات المجتمع في عصر العولمة. لبنان: دار الكتب العلمية. 
- الدرابكة، محمد مفضي؛ والبطوش، مصلح عبد الله. (2013). فاعلية برنامج تدريبي مستند إلى استراتيجية حل المشكلات المستقبلية في تنمية مهارات التفكير الناقد لدى الطلبة الموهوبين في الأردن. مجلة كلية التربية بالزقازيق، 1941)، 121 -934. الدرابكاة، محمد مفضي. (2017). برنامج حل المشكلات المستقبلية لتنمية التفكير الناقد والإبداعي. الدمام: مكتبة المتنبي. ذيب، هيثم عبد الله. (2016). أصول التخطيط الاستراتيجي. عمّان: دار اليازوري. الزعبي، إبراهيم أحمد. (2017). مدى تضمين محتوى كتب التربية الإسلامية لمهارات اتخاذ القرار لطلبة المرحلة

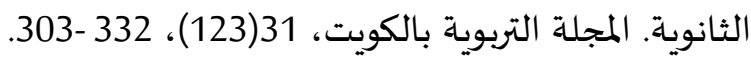
- - الزعبي، أحمد محمد. (2015). علم نفس النمو من الطفولة إلى الشيخوخة. الرياض: مكتبة الرشد ناشرون.

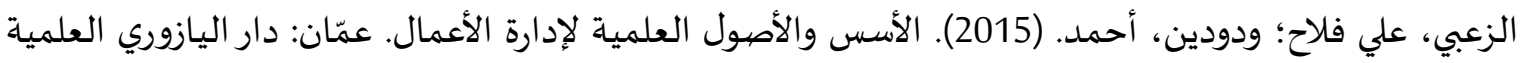
للنشر والتوزيع. السلوة، أشواق راشد. (2017). مهارات حل المشكلات لدى المعتمدات والمستقلات عن المجال الإدراكي من طالبات المرحلة الثانوية. رسالة ماجستير، جامعاة القصيم، المملكة العربية السعودية. السواط، وصل الله. (2010). فاعلية الذات وعلاقتها بمهارة اتخاذ القرار المهني لدى طلاب وطالبات الصفئه الأول الثانوي بمحافظة الطائف دراسة وصفية تنبؤية. مجلة كلية التربية، (66)، 347 -301.

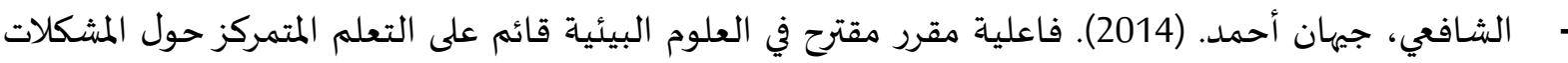
في تنمية مهارات التفكير المستقبلي والوعي والبيئي لدى طلاب كلية التربية جامعة حلوان. مجلة دراسات عربية فيكان في التربية وعلم النفس، (46)، 213 -180. شحادة، أمير وجياء. (2017). مستوى اتخاذ القرار الممني وعلاقته بالمناخ الأسري لدى طلبة المرحلة الثانوية في منطقة الناصرة. رسالة ماجستير، كلية العلوم التربوية والنفسية، عمان. - ـ الصاعدي، اعتدال حمد. (2012). النضج المهني وعلاقته بمهارات اتخاذ القرار المهني لطلاب وطالبات الثانوي. رسالة ماجستير، جامعة طيبة، المملكة العربية السعودية. الصقري، محمد ناصر؛ والبراشدية، حفيظة سليمان. (2013). العوامل المؤثرة على اتخاذ القرار المهني لدى طلبة الصف العاشر بمحافظة جنوب الباطنة. مجلة الآداب والعلوم الاجتماعية، (8)، 31 -15. عبد الحميد، هبة عبد الهادي. (2015). فاعلية استراتيجية حل المشكلات المستقبلية في تنمية التفكير الابتكاري في مادة الأحياء لدى طلاب الصف الأول الثانوي. مجلة القراءة والمعرفة، (187)، 199 -175.

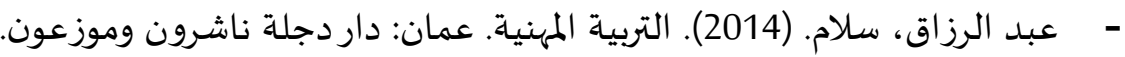
علي، حسين عباس حسين. (2011). تنظيم محتوى منهج العلوم وفق نموذج جويس وويل لمعالجة المعلومات وفاعليته في تنمية المفاهيم العلمية ومهارات اتخاذ القرار والتفكير الاستدلالي لدى تلاميذ الصف الخامس الابتدائي في المملكة العربية السعودية. مجلة دراسات في المناهج وطرق التدريس، (170)، 62 -15. علي، صباح أمين. (2013). فاعلية استخدام نموذج التحري الجماعي في تدريس القضايا الاجتماعية على تنمية

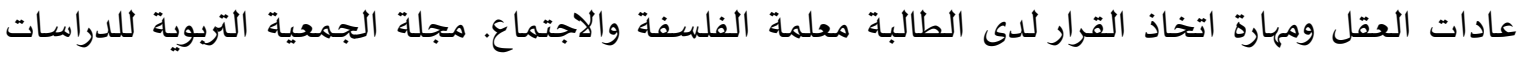

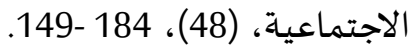


علي، محمد النوبي محمد. (2017). فعالية برنامج تدريبي قائم على حل المشكلات المستقبلية لتحسين الاستدلال العلمي في خفض قلق المستقبل لدى طلاب المرحلة الثانوية المتفوقين عقلياً. مجلة كلية التربية بجامعة الأزهر، .226- 318 ، (172)2

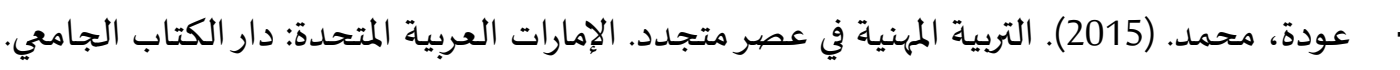

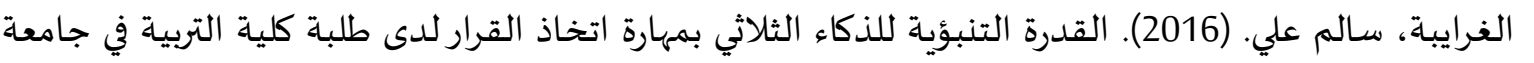

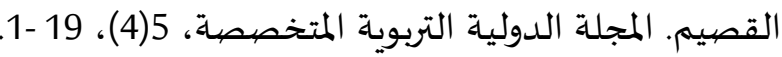
الكيلاني، ماجد عرسان. (2005). التربية والتجديد وتنمية الفاعلية عند العربي المعاصر. دبي: دار القلم.

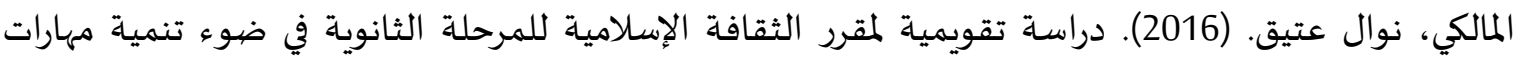

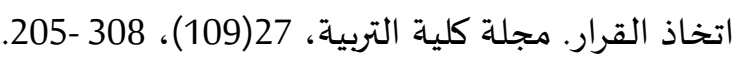

متولي، أحمد سيد. (2010). فاعلية حقيبة تعليمية إلكترونية قائمة على المدخل الوقائي في التدريس في تنمية

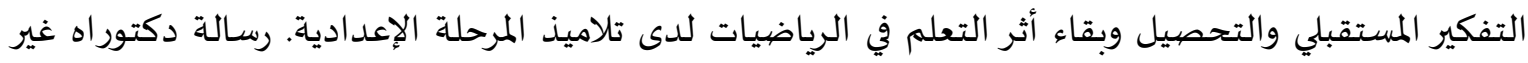
منشورة، جامعة القاهرة، مصر. محمد، آمال جمعاة عبد الفتاح. (2012). فاعلية برنامج مقترح في تدريس علم الاجتماع باستخدام التعلم الخدمي على تنمية المسؤولية الاجتماعية ومهارات اتخاذ القرار لدى الطلاب المعلمين في الفلسفة والاجتماع. مجلة الجمعية التربوية للدراسات الاجتماعية، (42)، 116 -53. المطيري، خالد. (2017). مهارات اتخاذ القرار وعلاقتها بالفاعلية الذاتية وأساليب التفكير السائدة لدى طلاب الداب جامعة القصيم. رسالة ماجستير، جامعة القصيم، المملكة العربية السعودية. منصور، عبد المجيد والتويجري، محمد والفقي، إسماعيل. (2014). علم النفس التربوي. الرياض: العبيكان للنشر. - الوسيهي، عماد الدين عبد المجيد. (2010). فاعلية برنامج مقترح في المستحدثات البيولوجية على التحصيل وتنمية ههارات اتخاذ القرار والاتجاه نحو هذه المستحدثات لدى تلاميذ المرحلة الإعدادياة. دراسات عربية في

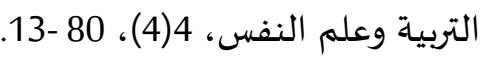
- الوكيل، حلهي أحمد؛ والمفتي، محمد أمين. (2014ه). أسس بناء المناهج وتنظيماتها. طV، عمان: دار المسيرة للنشر والتوزيع.

\section{ثانياً - المراجع بالإنجليزية:}

- Chiesa, R\&Massei, F \& Guglielmi, D. (2016). Career Decision- Making Self- Efficacy Change in Italian High School Students. Journal of Counseling \&Development, (94), 210- 226.

- Gregory, R\& Cleman, R. (2001). A Framework for Developing the Decision Making Skills of Secondary School Students. Decision Research, Eugene, Oregon.

- House. Ramani, G \&Brownell, C. (2014). Preschoolers cooperative problem solving: Integrating play and problem solving. Journal of Early Childhood Research, 12(1), 92-108. 